\title{
Numerical Simulation Study on Root Stones Loss in Dam Buttress Engineering
}

\author{
Chi Yao $\mathbb{D},{ }^{1}$ Changming Yang, ${ }^{1}$ Yan Lan $\left(\mathbb{D},{ }^{2}\right.$ Qinghui Jiang, \\ Shuihua Jiang, ${ }^{1}$ and Jianhua Yang $\mathbb{D}^{1}$ \\ ${ }^{1}$ School of Civil Engineering and Architecture, Nanchang University, Nanchang 330031, China \\ ${ }^{2}$ Yellow River Institute of Hydraulic Research, Yellow River Conservancy Commission of the Ministry of Water Resources, \\ Zhengzhou 450003, China \\ Correspondence should be addressed to Yan Lan; 18091025@qq.com
}

Received 2 July 2018; Revised 5 November 2018; Accepted 15 November 2018; Published 2 December 2018

Academic Editor: Damijan Markovic

Copyright (C) 2018 Chi Yao et al. This is an open access article distributed under the Creative Commons Attribution License, which permits unrestricted use, distribution, and reproduction in any medium, provided the original work is properly cited.

\begin{abstract}
In order to study the loss of root stones under action of water flow in dam buttress, based on Flow-3D, a mathematical model was established. At first, the physical experiment was carried out about water drag force on a $0.04 \mathrm{~m} \times 0.04 \mathrm{~m} \times 0.04 \mathrm{~m}$ cubic block. And then a numerical flume model about this experiment was established in Flow-3D software. The values of drag force were compared between the numerical and experimental results, and the percentage of error was less than 5\%. Thus, the numerical model in Flow3D was accurate and available. Then, a numerical simulation on root stones loss in an actual dam buttress project was carried out. Since the actual flow is turbulent, the RNG $k-\varepsilon$ turbulence model was used. And VOF method, FAVOR technology, and GMO model were also used in this simulation. The numerical results showed flow depth, pressure, velocity, turbulent energy, and root stones loss. Because water level of the inflow increased with time continuously, flow depth and velocity also increased, and the root stones would be lost. The increase in flow velocity was the fastest in the dam head, and the start time of root stones loss was also the earliest. The most serious area of root stones loss is the dam head, and the serious second area is the upper cross corner. Those root stones would have the farthest lost distance in the dam head. The root stones loss was also serous in the upstream face. However, the root stones in the upstream face and the down cross corner were less affected by water flow, so there were no root stones loss phenomena. Thus, in the actual project, the dam head, the upper cross corner, and the upstream face should get more attention.
\end{abstract}

\section{Introduction}

Dam buttress is the river control work that resists the water flow to erode the embankment directly. Dam buttress is the important part of the Yellow River flood control structural systems. In the river training works of the Yellow River, we always scatter stones at the bottom of the dam, the buttress, and the riverbank. These stones are called root stones. Root stones will withstand the impact of the water flow to protect the dam buttress, and they will be washed away. The stability of the dam buttress engineering can directly affect the safety of the embankment, but the stability of the dam root stones can directly affect the safety of the dam buttress. In the actual engineering, parts of the dangerous works are not designed completely, but they were achieved during the flood season by continuously slipping, grabbing, and protecting. When these dangerous works are washed strongly by deflected current and swirl flow, the dam root stones will be lost. If the root stones loss is serious and not discovered and rescued in time, there will be some dangerous omens, such as cracking, collapsing, pier sting, or slipping, which will eventually cause the risk of dam.

At present, the main studies on the root stones loss are the root stones detection in the actual engineering and corresponding physical experiment. Zhang et al. [1] carried out a physical model on several different measures to protect root stones, analyzed advantages, disadvantages and applicable conditions of several measures, and put forward a measure of using nets to protect root stones which provided technical support for the regulation of the root stone slope 
protection in the actual project. Zhang [2] calculated the calculation formulas of different scouring pits and compared the calculation results with the results of model test. Then, he analyzed the adaptability of each formula under different working conditions, observed the root stones of different parts of spur dikes, and got the laws of root stones loss with the formation of scouring pits in spur dikes and the reasons for the root stones loss. Gou [3] established the physical model about the root stones loss, derived the force calculation formulas of natural river root stones loss, and got the result that the critical starting dimension of root stones increased with the increase in sediment concentration and water flow velocity. Zhang et al. [4] pointed out that the root stones loss is closely related to the characteristics of the dam bank, the formation of the scouring pit, the starting velocity of root stones, and the slope of root stones according to analyzing the root stones detection data of 60 dangerous dam buttress sections in Jinan City from 1997 to 1999.

Because the Yellow River is the high sediment flow, and the root stones detection technology is limited at present, the deformation and the range of the influence of root stones loss are most still in the empirical judgment [5-7]. At present, the physical experiments on the analysis of rock masses subjected to water flow force have achieved obvious results, such as the study of broken rocks [8], bank revetment blocks [9], flood-submerged bridges $[10,11]$, and sandbags in the process of throwing water into the water [12]. Numerical simulation has been widely used in engineering [13-15], especially the flow characteristic $[16,17]$. The FLOW-3D software also plays an important role [18-22]. Root stones loss is actually a large granular displacement problem under the impact of water flow, which is essentially a fluid-solid coupling motion. Because of the consideration of the flow change and root stones movement, the turbulence model and the GMO model are selected to get more accurate results in the FLOW-3D. And because the empirical judgment is not largely inaccurate and the root stones detection is dangerous and wasteful in the actual engineering, however the numerical simulation can get accurate results and save great amount of manpower and material resources. Only a few people have done this type of numerical research on the root stones with FLOW3D software, so this research is innovative. And the results of numerical simulation can be used as the actual engineering references.

\section{Materials and Methods}

2.1. Continuity Equations. FLOW-3D software uses the Navier-Stokes equation as the control equation of incompressible fluid motion and uses rectangular grid cells to divide the computing area. The unique software FAVOR technology [23] adds area fraction and volume fraction in the calculated model equation. The model formula is based on Cartesian coordinating system.

Continuous equation:

$$
\frac{\partial\left(u A_{x}\right)}{\partial x}+\frac{\partial\left(v A_{y}\right)}{\partial y}+\frac{\partial\left(w A_{z}\right)}{\partial z}=0
$$

Momentum equations:

$$
\begin{aligned}
\frac{\partial u}{\partial t} & +\frac{1}{V_{F}}\left\{u A_{x} \frac{\partial u}{\partial x}+v A_{y} \frac{\partial u}{\partial y}+w A_{z} \frac{\partial u}{\partial z}\right\} \\
& =-\frac{1}{\rho} \frac{\partial p}{\partial x}+G_{x}+f_{x} \\
\frac{\partial v}{\partial t} & +\frac{1}{V_{F}}\left\{u A_{x} \frac{\partial v}{\partial x}+v A_{y} \frac{\partial v}{\partial y}+w A_{z} \frac{\partial v}{\partial z}\right\} \\
& =-\frac{1}{\rho} \frac{\partial p}{\partial y}+G_{y}+f_{y} \\
\frac{\partial w}{\partial t} & +\frac{1}{V_{F}}\left\{u A_{x} \frac{\partial w}{\partial x}+v A_{y} \frac{\partial w}{\partial y}+w A_{z} \frac{\partial w}{\partial z}\right\} \\
& =-\frac{1}{\rho} \frac{\partial p}{\partial z}+G_{z}+f_{z}
\end{aligned}
$$

where $u, v, w$ are the current velocity components in $x, y, z$ direction, respectively; $A_{x}, A_{y}, A_{z}$ are fractional areas open to flow; $G_{x}, G_{y}, G_{z}$ are body acceleration values in $x, y, z$ direction, respectively; $f_{x}, f_{y}, f_{z}$ are viscous acceleration values in $x, y, z$ direction, respectively; $V_{F}$ is fractional volume open to flow; $\rho$ is density of the fluid; and $P$ is pressure field.

2.2. Turbulence Model. FLOW-3D offers some turbulence models, such as normal turbulence models, $k-\varepsilon$ turbulence model, and RNG turbulence model. RNG $k-\varepsilon$ turbulence model is widely used in the simulation of complex water flow $[24,25]$. This model is proposed by Yakhot and Orszag [26], which is the unsteady N-S equation. The resulting equation is the same as $k-\varepsilon$ turbulence model. However, the RNG turbulence model is the most accurate model in FLOW-3D software [27], and the features and advantages of RNG $k-\varepsilon$ turbulence model are over other $k-\varepsilon$ models [28]. So RNG $k-\varepsilon$ turbulence model was used in this paper. The governing equations of the turbulence model are as follows:

Turbulent energy $k$ equation:

$$
\frac{\partial(\rho k)}{\partial t}+\frac{\partial\left(\rho k u_{i}\right)}{\partial x_{i}}=\frac{\partial}{\partial x_{j}}\left[\left(\mu+\frac{\mu_{t}}{\sigma_{k}}\right) \frac{\partial_{k}}{\partial x_{j}}\right]+G_{k}+\rho \varepsilon
$$

Turbulent energy dissipation rate $\varepsilon$ equation:

$$
\begin{aligned}
\frac{\partial(\rho \varepsilon)}{\partial t}+\frac{\partial\left(\rho \varepsilon u_{i}\right)}{\partial x_{i}}= & \frac{\partial}{\partial x_{j}}\left[\left(\mu+\frac{\mu_{t}}{\sigma_{\varepsilon}}\right) \frac{\partial \varepsilon}{\partial x_{j}}\right]+\frac{C_{1 \varepsilon}^{*}}{k} G_{k} \\
& -C_{2 \varepsilon} \frac{\varepsilon^{2}}{k} \\
G_{k}= & \mu_{t}\left(\frac{\partial u_{i}}{\partial x_{j}}+\frac{\partial u_{j}}{\partial x_{i}}\right) \frac{\partial u_{i}}{\partial x_{j}} \\
C_{1 \varepsilon}^{*} & =C_{1 \varepsilon}-\frac{\eta\left(1-\eta / \eta_{0}\right)}{1+\beta \eta^{3}}
\end{aligned}
$$



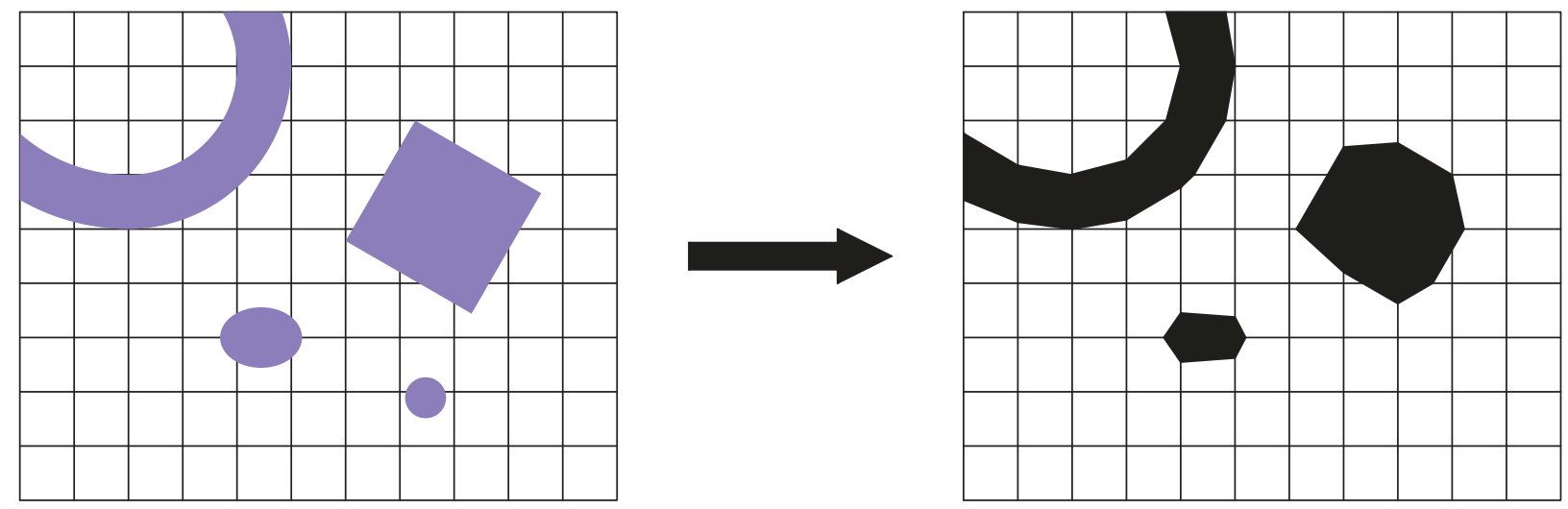

Figure 1: Object definition (left) and object created (right).

$$
\begin{gathered}
\eta=\left(2 E_{i j} \cdot E_{i j}\right)^{1 / 2} \frac{k}{\varepsilon} \\
E_{i j}=\frac{1}{2}\left(\frac{\partial u_{i}}{\partial x_{j}}+\frac{\partial u_{j}}{\partial x_{i}}\right)
\end{gathered}
$$

where $k$ is turbulent energy; $\varepsilon$ is turbulent energy dissipation rate; $\mu_{i}$ is turbulent kinematic viscous coefficient, $\mu_{i}=$ $C_{\mu} k^{2} / \varepsilon, C_{\mu}=0.085 ; \sigma_{k}=\sigma_{\varepsilon}=0.7179 ; G_{k}$ is the generation of turbulent energy $k ; C_{1 \varepsilon}=1.42 ; C_{2 \varepsilon}=1.68 ; \eta_{0}=4.377$; and $\beta=$ 0.012 .

2.3. VOF Method. The VOF (volume of fluid) method is the method of tracking free surface proposed by Hirt and Nichols [29]. The VOF method is employed in FLOW-3D, and it consists of three main components: the definition of the volume of fluid function, a method to solve the VOF transport equation, and setting the boundary conditions at the free surface. The VOF transport equation is (8). The interpretation of $F$ depends on the type of problem being solved. For a single fluid, $F$ represents the volume fraction occupied by the fluid. Fluid exists where $F=1$, and void regions correspond to locations where $F=0$. And for two-fluid problems, which may be composed of two incompressible fluids or one incompressible and one compressible fluid, $F$ represents the volume fraction of the incompressible fluid component in either case.

$$
\frac{\partial F}{\partial t}+\frac{1}{V_{F}}\left[\frac{\partial\left(F A_{x} u\right)}{\partial x}+\frac{\partial\left(F A_{y} v\right)}{\partial y}+\frac{\partial\left(F A_{z} w\right)}{\partial z}\right]=0
$$

2.4. FAVOR Technology. FLOW-3D uses FAVOR technology (Fractional Area/Volume Obstacle Representation) to define the calculation area, and this technology was proposed by Hirt and Sicilian [30]. This method computes the open area fractions of the cell faces along with the open volume fraction and reconstructs the geometry based on these parameters. This approach offers a simple and accurate way to represent complex surfaces in the domain without requiring a bodyfitted grid. FAVOR technology adjusts the object geometry according to the calculation results and can describe complex geometric models by using simple rectangle grid [31]. However, FAVOR is affected by the resolution of the computation, as shown in Figure 1. This is because the preprocessor generates area fractions for each cell face in the grid by determining which corners of the face are inside of a defined geometry. If all four corners of a cell face are inside the geometry, then the entire face is defined to be within the geometry. Similarly, if all corners lie outside, then the entire face is assumed to be outside the geometry.

2.5. GMO Model. The basic principle of root stones loss is the fluid-solid coupling motion under the action of water flow. The GMO model is used to calculate the moving object in FLOW-3D. The GMO model allows the object to collide during the movement. The collision is thought to occur instantaneously. The collision model is divided into two parts: collision detection and collision integration. In the process of calculation, the collision is detected and the latter series of collision equations will be integrated. Collision can be divided into perfect elastic collision, partial elastic collision, and complete plastic collision based on collision coefficient. The model also provides the setting of object friction coefficient.

2.6. Model Establishment. Establishing a physical experimental flume model: this flume was carried out in Yellow River Institute of Hydraulic Research, Yellow River Conservancy Commission of the Ministry of Water Resources. Figure 2 provides an illustration about the experiment. Figure 3 shows the process of water-level rises. And the experiment begins when the water level is $0.25 \mathrm{~m}$.

Establishing a simple numerical sink model as shown in Figure 4: the sink model is 3 meters long and 0.6 meters wide. There is a 0.04 meters long fixed cube block in the middle of the tank. The inlet flow rate is shown in Table 1; the east, west, and bottom boundary conditions are wall; the outlet boundary condition is free flow; the atmospheric pressure above the calculation area is a standard atmospheric pressure. The grid is $0.01 \mathrm{~m} \times 0.01 \mathrm{~m} \times 0.01 \mathrm{~m}$ rectangular structured 


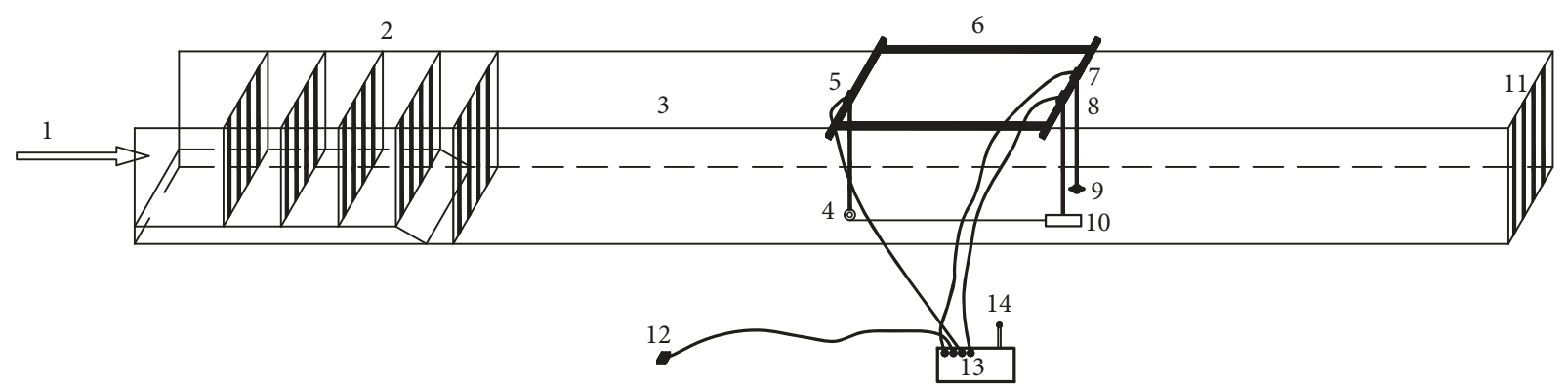
1. Water flow direction
2. Energy dissipation grille
3. Flume
4. Pulley
5. Drag force sensor
6. Frame
7. Flow rate sensor

8. Vertical force sensor

9. Propeller current meter

10. Block

11. Tailgate

12. Water pressure sensor

13. Signal converter

14. Wireless sensor

FIGURE 2: Layout of physical experimental model.

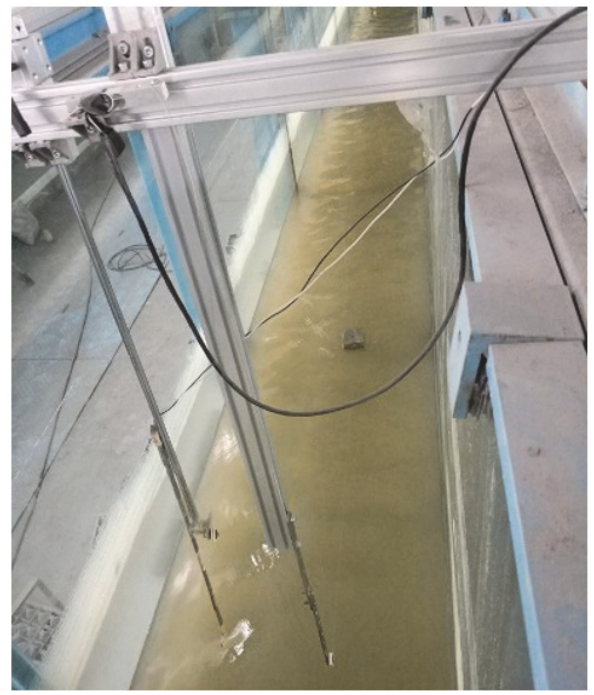

(a)

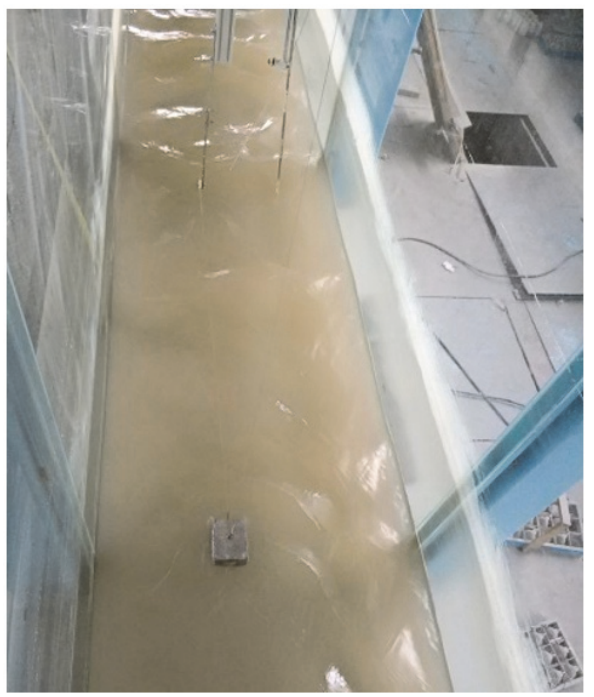

(b)

FIgURE 3: Layout of water-level rises in flume experiment. (a) Front. (b) Back.

TABLE 1: Test conditions and drag force.

\begin{tabular}{lccccc}
\hline $\begin{array}{l}\text { Simulation time } \\
(\mathrm{s})\end{array}$ & Water depth $(\mathrm{m})$ & Block size $(\mathrm{m})$ & $\begin{array}{c}\text { Average velocity } \\
(\mathrm{m} / \mathrm{s})\end{array}$ & \multicolumn{2}{c}{$\begin{array}{c}\text { Drag force } \mathrm{F}_{\mathrm{D}}(\mathrm{N}) \\
\text { Simulated value }\end{array}$} \\
\hline & & 0.25 & 0.053 & 0.057 & Percentage of error \\
& & & 0.35 & 0.098 & 0.102 \\
360 & \multirow{2}{*}{0.25} & $0.04 \times 0.04 \times 0.04$ & 0.45 & 0.145 & 0.166 \\
& & 0.55 & 0.211 & 0.240 \\
& & 0.65 & 0.307 & 0.335 \\
\hline
\end{tabular}




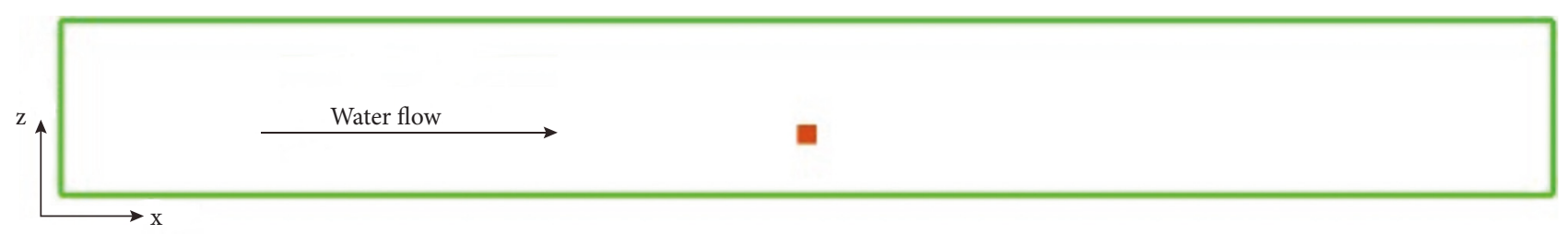

(a)

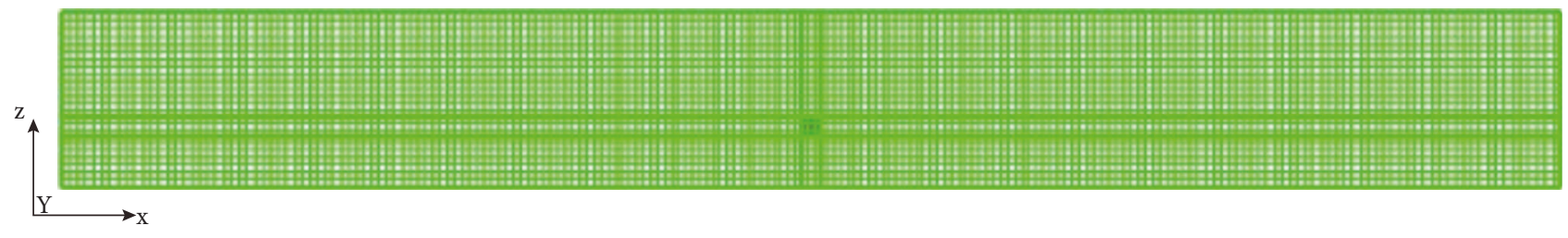

(b)

Figure 4: Numerical sink model. (a) Model layout. (b) Mesh generation.

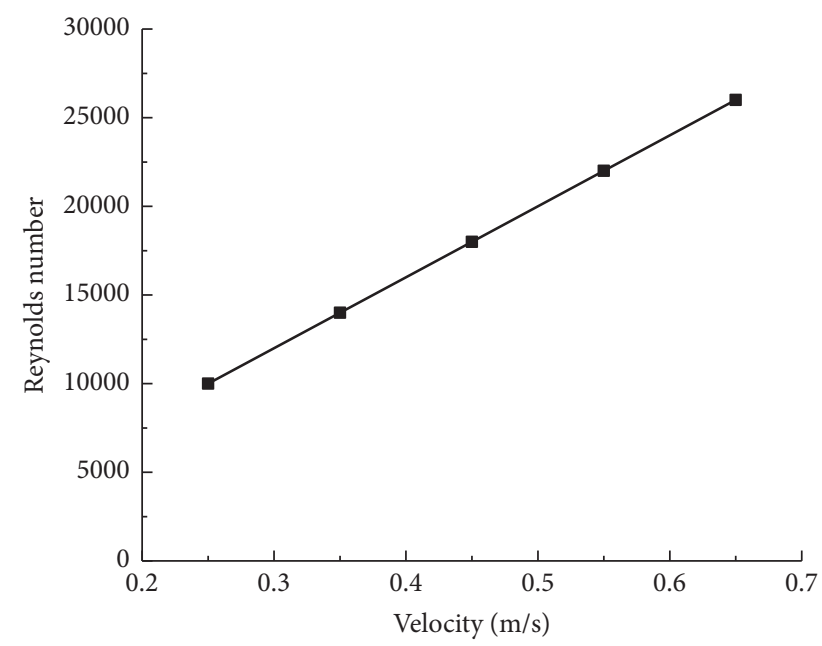

FIgURE 5: Reynolds number fitting curves.

grid, and the total number of grids is about 660,000 . The gravitational acceleration is $-9.81 \mathrm{~m} / \mathrm{s}^{2}$.

2.7. Analysis of Results. There is comparison between the numerical and experimental results about drag force in Table 1 and Figure 6. Evett and Liu [32] thought that when the Reynolds number $\rho U d / \mu=\operatorname{Re}>1000$, the object aspect ratio was 1.0, and the drag force coefficient $C_{D}=1.05$. The equivalent particle size of the mass is $d=0.124 \mathrm{~m}$ [33]. The shape Reynolds number of the block in different velocity conditions is shown in Figure 5. Figure 6 shows the drag force of experimental value and calculated value. The simulated value is slightly larger than the experimental value. But their percentage of error is $4.15 \%$, so this means that the established model on the drag force calculation is accurate.

\section{Results and Discussion}

3.1. Engineering Case. Shundi control and extension project is in Yongji City, Shanxi Province, China, as shown in Figure 7.

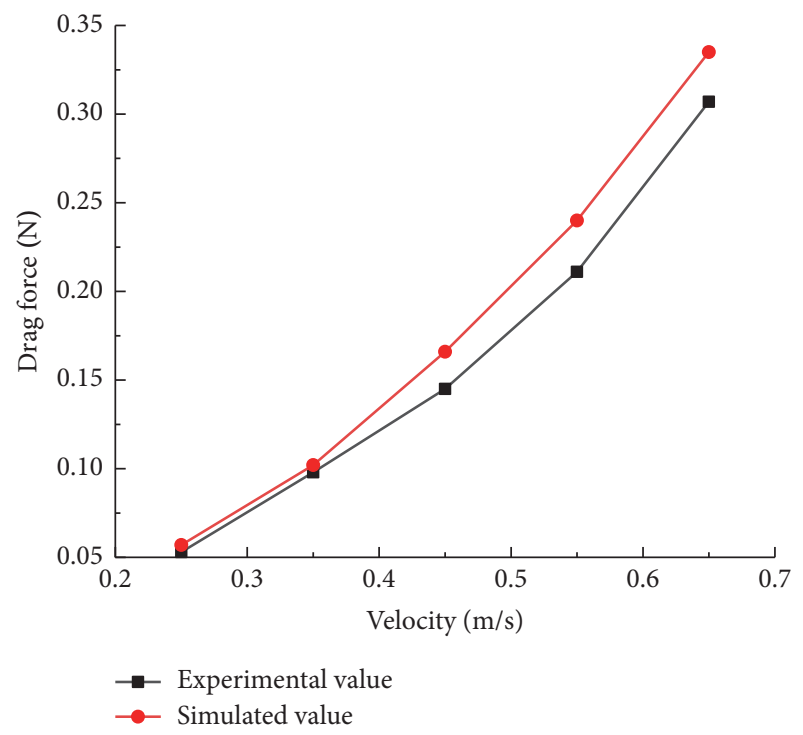

FIgURE 6: Drag force of experimental value and simulated value.

Shundi control and extension project is $1000 \mathrm{~m}$ long, and there are 13 dam buttresses. The designed dam crest elevation is $342.40 \mathrm{~m}-342.10 \mathrm{~m}$, and the average dam height is 3.90 $\mathrm{m}$. The fortification is designed according to the horizontal annual discharge $4000 \mathrm{~m}^{3} / \mathrm{s}$ in 2020 . The design flood level is $341.32 \mathrm{~m}$, and the construction water level is $339.98 \mathrm{~m}$. Figure 8 shows the layout of the engineering plane. Figure 9 shows the plane size and cross-sectional dimension of the dam buttress. The project uses a combination of dam and buttress. There are 13 dam buttresses in all, and the distance between adjacent dam buttresses is $80 \mathrm{~m}$. The angle of upstream face and connecting dam axis is $30^{\circ}$, and the angle of dam back and connecting dam axis is $60^{\circ}$. The dam head is an arc with a radius of 15 meters. The buttress and connecting upstream face are covered with stones. The top of the connecting dam soil is $10 \mathrm{~m}$ wide. The slope of stone revetment is 1:1.5, and the slope of scattered root stones is 1:1. 


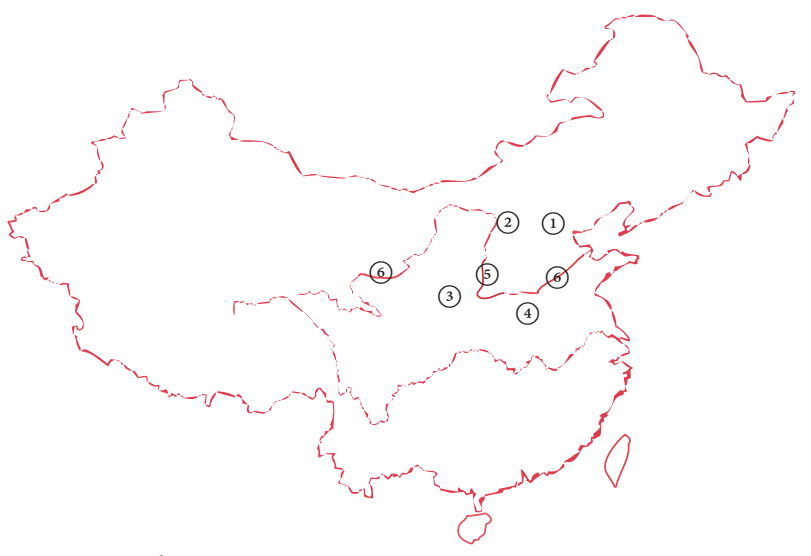

(1) Beijing, China

(2) Shanxi Province

(3) Shanxi Province

(4) Henan Province

(5) Shundi control and extension project, Yongji City

(6) Yellow River

FIGURE 7: The location of Shundi control and extension project.

3.2. Model Establishment. Create a physical model of the dam slope with the ratio 1:1 according to the actual project's plane size and cross-sectional dimension of the dam buttress shown in Figure 10. The dams in the project are basically the same, and two dam buttresses were selected to analyze. In the actual project, the slope protection of root stones is the accumulation body. The accumulation form is varied and complex. In this paper, we study the root stones loss under the action of water flow and select the single row root stones around the dam buttress. As shown in Figure 10, the single row root stones are evenly distributed in the extension of the root stones slope protection. The root stone is a cube whose diameter is $50 \mathrm{~cm}$ and density is $2700 \mathrm{~kg} / \mathrm{m}^{3}$. The dam buttress is divided into upstream face, upper cross corner, dam head, and down cross corner, and the root stones in these areas are marked with different colors.

3.3. Model Meshing. Import the built entity model into the FLOW-3D software. And the structured rectangular meshes are used to divide the model as shown in Figure 11. The length of the calculation area is $190 \mathrm{~m}$, the width is $35 \mathrm{~m}$, the height is $2 \mathrm{~m}$, the grid size is $0.25 \mathrm{~m} \times 0.25 \mathrm{~m} \times 0.25 \mathrm{~m}$, and the total grid number is about 1.1 million. To control the stability of the flow at the outlet, two tail piers are added at the end of the calculation area to control the flow of water. The gravitational acceleration in the calculated area is set to $-9.81 \mathrm{~m} / \mathrm{s}^{2}$.

3.4. Moving Root Stones Properties Setting. In the GMO model, the root stones movement is set under the action of water flow. The collision and friction between root stones is considered in the calculation process. The friction factor of the root stone and the bottom is 0.4 [34] considered to be the friction of the riprap basement and silt sand foundation soil. The collision coefficient is 0.1 . The density of the root stone is set at $2700 \mathrm{~kg} / \mathrm{m}^{3}$. Each root stone is set to have six degrees of
TABLE 2: Coordinate position of each monitoring point (unit: $\mathrm{m}$ ).

\begin{tabular}{lccc}
\hline Monitoring points & $\mathrm{x}$ & $\mathrm{y}$ & $\mathrm{z}$ \\
\hline 1 & 55 & 15 & 0.5 \\
2 & 68 & 22.5 & 0.5 \\
3 & 80 & 26 & 0.5 \\
4 & 99 & 19 & 0.5 \\
5 & 117 & 11 & 0.5 \\
6 & 129 & 11 & 0.5 \\
\hline
\end{tabular}

freedom. The root stone movement form is coupled motion, so root stones can move or even roll with the water flow. The root stones movement can also affect the change of the flow regime.

3.5. Boundary Conditions and Monitoring Point Settings. Conditions setting: according to the relative water level of the actual project, the bottom of the river bed is set as the reference surface. So the elevation is $0 \mathrm{~m}$, the construction water level is $0.5 \mathrm{~m}$, and the design flood level is $1.84 \mathrm{~m}$. The depth of the entrance boundary is set from $0.5 \mathrm{~m}$ to $1.84 \mathrm{~m}$ within $300 \mathrm{~s}$ and then maintained at $1.84 \mathrm{~m}$. The outlet boundary is set as outflow boundary. And the volume flow rate of inflow and outflow can be seen in Figure 12. The two walls and the bottom are set as wall boundary. Above the calculation area is a standard atmospheric pressure. The calculation time is $360 \mathrm{~s}$.

In order to compare the water flow calculation results in different areas, the monitoring points are set around the dam buttress as shown in Figure 13. The information on water flow such as flow velocity in the calculation is extracted and analyzed. The coordinate position of each monitoring point is shown in Table 2.

3.6. Flow Field and Stream Lines. Figure 14 shows the flow pattern and stream lines at different times. The water flow rate is calculated with the increase of the water level at the entrance boundary. In Figure 14(a), the water flow passes through the dam buttress at $t=50 \mathrm{~s}$. When the water flow passes though the upstream face, the direction of stream lines is changed. Due to the narrow beam role of the dam buttress, the water flow is squeezed and flows along the dam body. The flow rate is gradually increased along the dam body, and the water flows into the dam crotch. At $t=150 \mathrm{~s}$, the flow velocity in the dam head is obviously changed, and this flow velocity is the largest in the calculation area. The water flow is divided into two parts after passing though the dam head. Part of the water flows to the side of the dam and flows downstream, while another part of the water flows around the dam head and into the dam crotch. Because of the increase of the flow velocity, the water flow is affected by the centrifugal force and forms a counterclockwise whirlpool in the down cross corner. At $t=250 \mathrm{~s}$, the part of root stones movement causes a significant effect on the water flow. And there is a complicated vortex in the dam crotch, which causes the root stones to move in the connecting dam section. At $t=350 \mathrm{~s}$, the water depth of the inflow boundary reaches the design flood level, and the water flow has been over the top of the first 


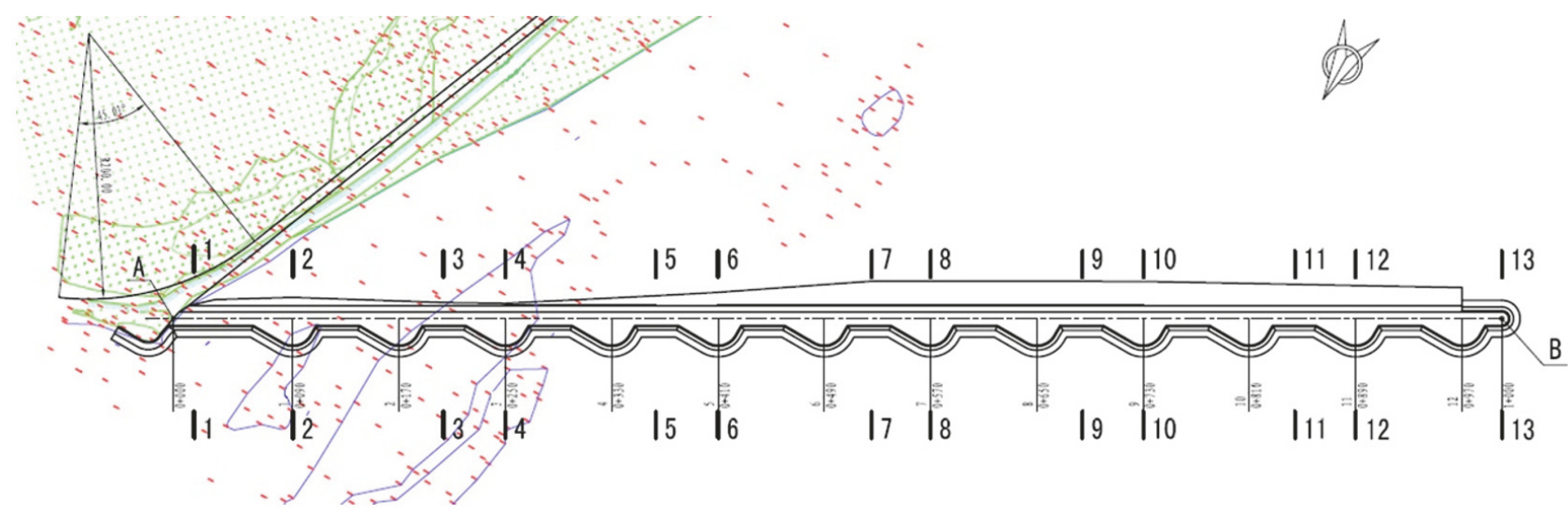

FIGURE 8: The layout of engineering plane.

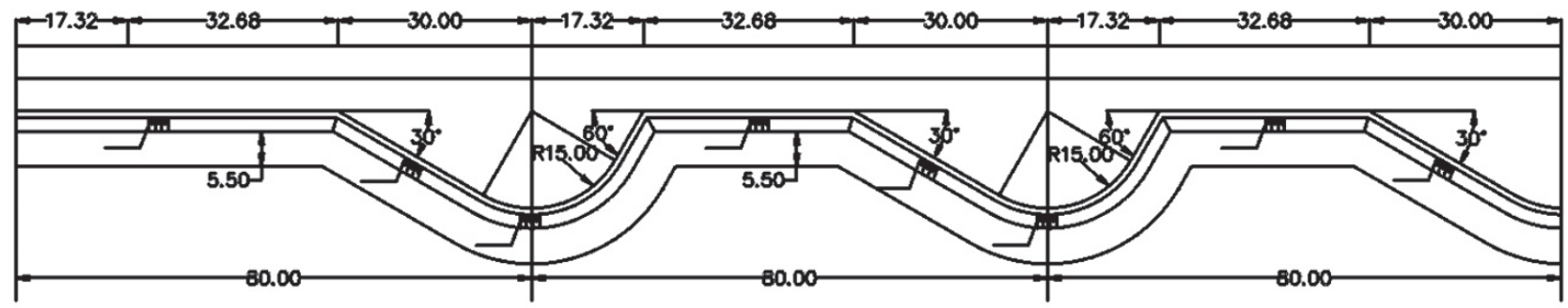

(a)

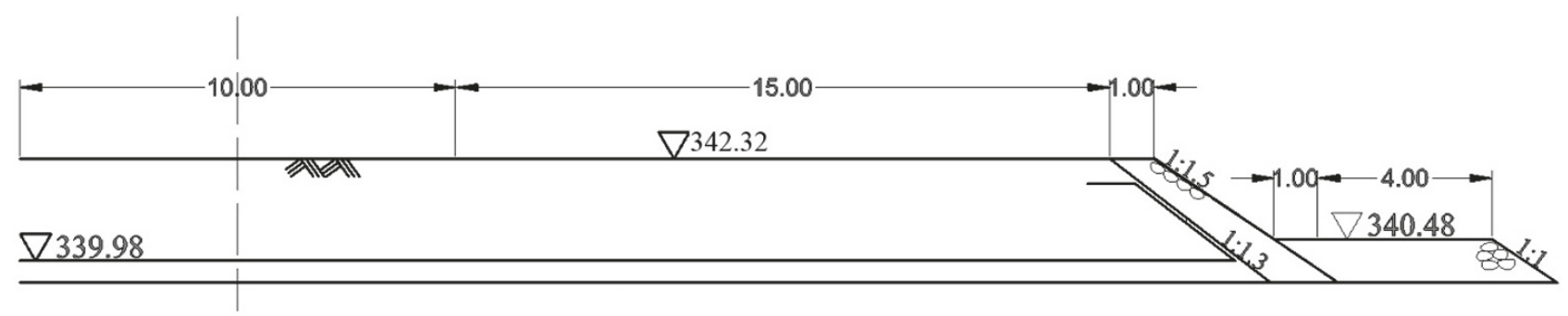

(b)

Figure 9: Layout of dam buttress. (a) Plane size (unit: $\mathrm{m}$ ). (b) Cross-sectional dimension (unit: $\mathrm{m}$ ).

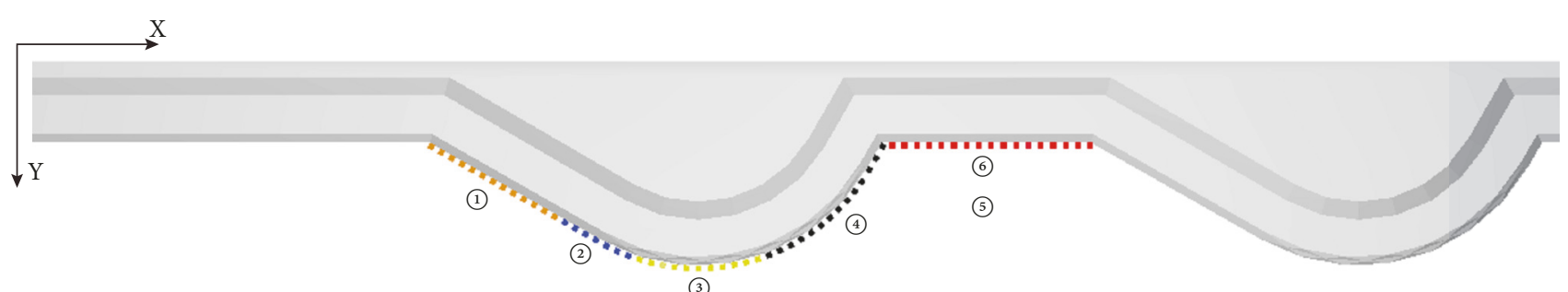

(3)
(1) Upstream face
(4) Down cross corner
(2) Upper cross corner
(5) Dam crotch
(3) Dam head
(6) Connection dam section

FIGURE 10: Layout of dam buttress root stones. 


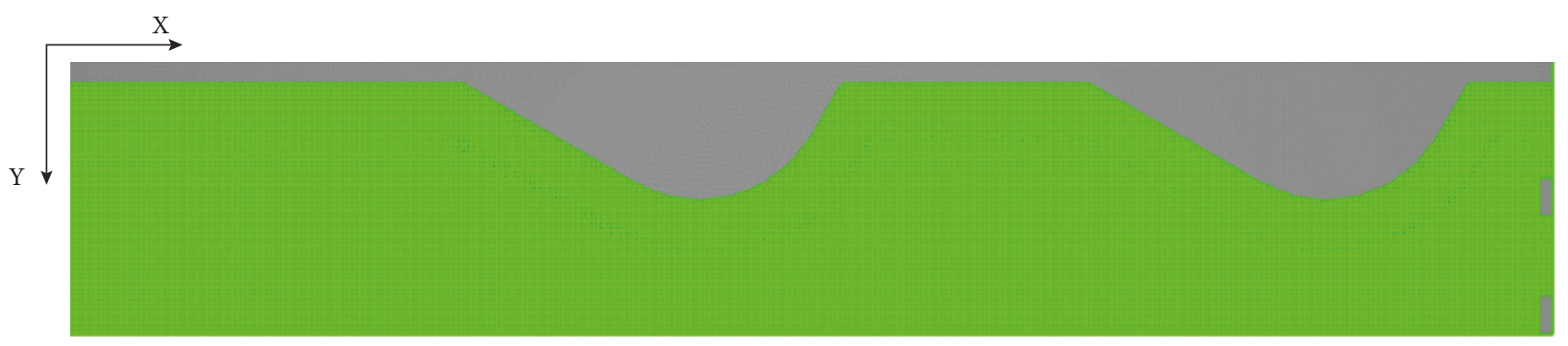

FIGURE 11: Diagram of mesh division.

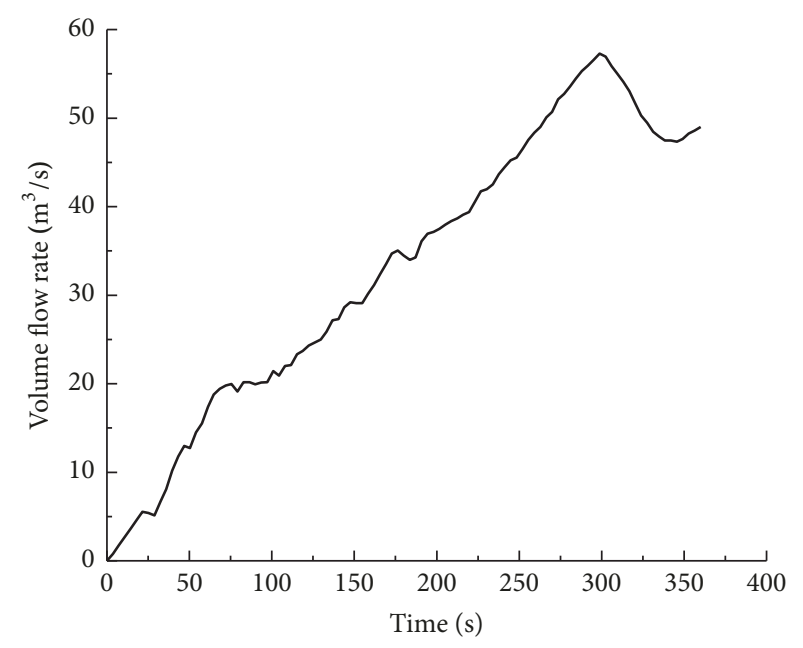

(a)

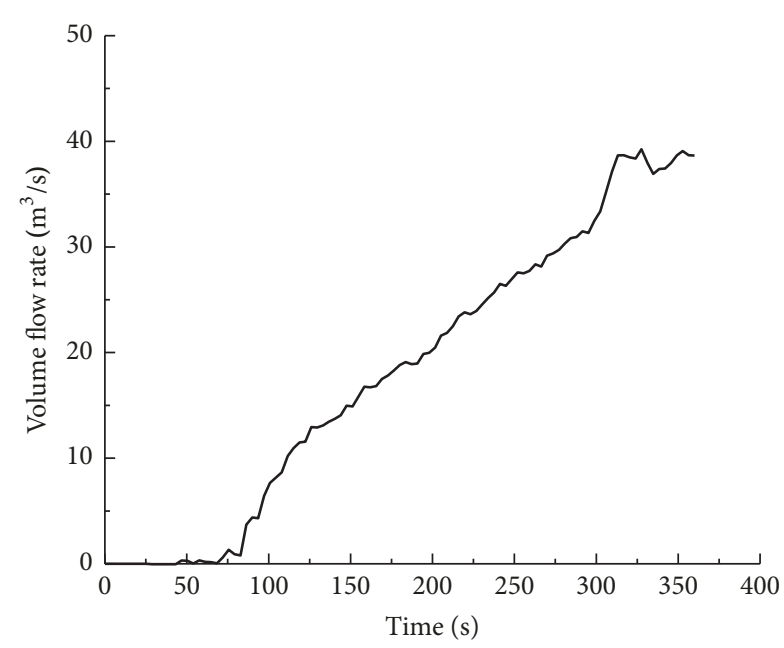

(b)

Figure 12: Volume flow rate. (a) Inflow. (b) Outflow.

slope protection of dam buttress root stones. Some root stones accumulate in the down cross corner, and the accumulation of root stones reduces the rate of water flow in the dam crotch. The accumulation of root stones directly affects the spread of the water flow in the dam crotch, so it is difficult to observe the whirlpool in the dam crotch.

3.7. Analysis of Pressure and Depth. Figure 15 shows the pressure of the water flow, and Figure 16 shows the water depth. At $t=50 \mathrm{~s}$, the lowest pressure is generated in the area in front of the first dam buttress, and the pressure is close to 0 . The pressure is close to $1500 \mathrm{~Pa}$ in the other area. And the water depth is $0.5 \mathrm{~m}$ in the whole simulation area. At $\mathrm{t}$ $=150 \mathrm{~s}$, the lowest pressure is generated in two areas. One is in front of the first dam buttress, and the other is in front of the second dam buttress. But in the dam head, there are small areas where the lowest pressure is generated. Because the water level rises, the water depth is deeper. In the first dam buttress, the water depth is close to $1 \mathrm{~m}$ in the upstream face and the upper cross corner. But due to the narrow beam role of the dam buttress, there is a height difference in the dam head, and the height difference is close to $0.5 \mathrm{~m}$. At $\mathrm{t}=250 \mathrm{~s}$, the lowest pressure is generated in the dam cross corner and the dam crotch and around the second dam buttress. And at this time, the water depth is about $1.5 \mathrm{~m}$ in front of the first dam buttress and $1 \mathrm{~m}$ in the dam crotch. At $\mathrm{t}=350 \mathrm{~s}$, the lowest pressure is generated mainly around the second dam buttress, and the pressure increases in the dam crotch of the first dam buttress. The water depth increases continuously. The water depth is about $2 \mathrm{~m}$ in front of the first dam buttress and $1.5 \mathrm{~m}$ in the dam crotch. With the increase in water level, the water pressure changes in different area, and the water depth increases continuously. However, the height difference is almost constant, and the value is close to $0.5 \mathrm{~m}$.

3.8. Analysis of the Monitoring Points Flow Velocity. Figure 17 shows the flow velocity at each monitoring point during the entire calculation. At monitoring 1, the water flow velocity increases steadily in the upstream face. The water flow varies smoothly in the calculation process, and the maximum flow velocity is close to $1 \mathrm{~m} / \mathrm{s}$. At monitoring point 2 , since the inlet water level rises and the dam buttress is continuously narrowed, the flow velocity increases gradually and the maximum flow velocity is close to $1.6 \mathrm{~m} / \mathrm{s}$. At monitoring point 3 , the flow velocity varies greatly. The velocity at this monitoring point rises faster at the early time, the velocity reaches about $2.2 \mathrm{~m} / \mathrm{s}$ at $\mathrm{t}=100 \mathrm{~s}$, and then the velocity plummets at $t=120 \mathrm{~s}$. The water flow velocity at this monitoring point is affected by the movement dam root stones. With the root stones moving downwards, the flow velocity is restored and gradually increases. And the maximum flow velocity is around $3.0 \mathrm{~m} / \mathrm{s}$. Monitoring point 4 is located in the down 


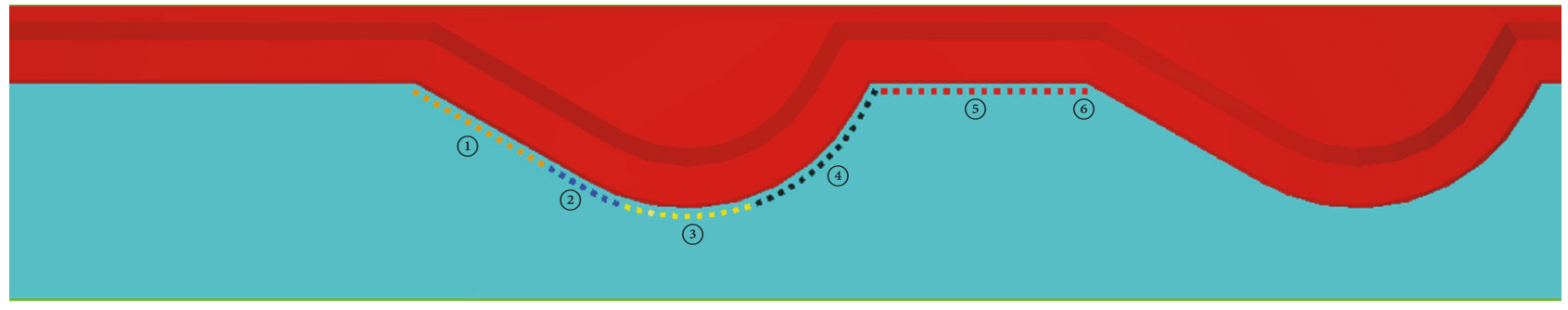

(1) Monitoring point 1
(2) Monitoring point 2
(3) Monitoring point 3

(4) Monitoring point 4

(5) Monitoring point 5

(6) Monitoring point 6

FIGURE 13: Layout of model and monitoring points described by FAVOR technology.

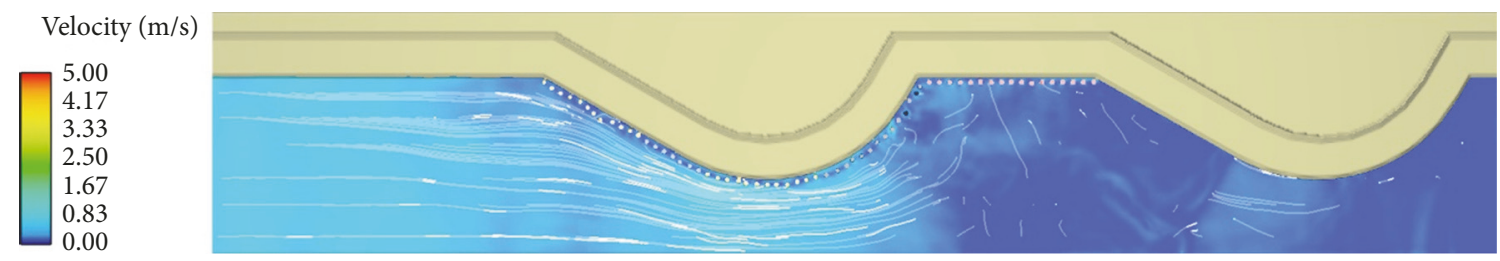

(a)

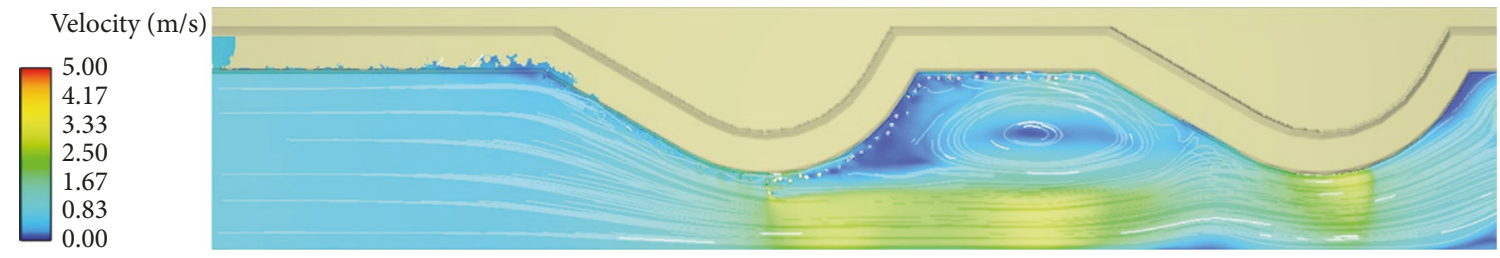

(b)

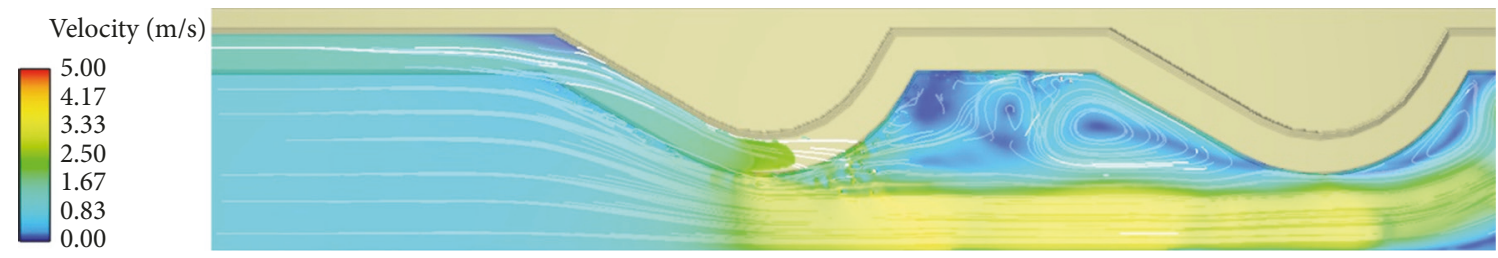

(c)

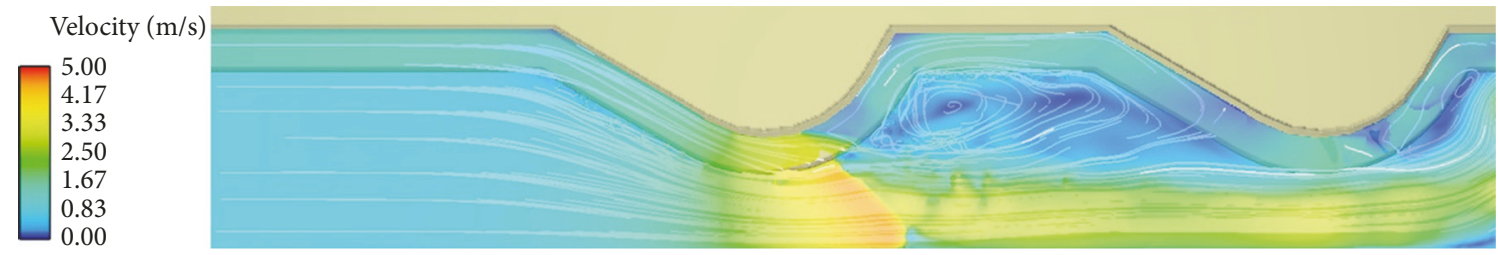

(d)

Figure 14: Flow field and stream lines. (a) $\mathrm{T}=50 \mathrm{~s}$. (b) $\mathrm{T}=150 \mathrm{~s}$. (c) $\mathrm{T}=250 \mathrm{~s}$. (d) $\mathrm{T}=350 \mathrm{~s}$.

cross corner. And at monitoring point 4, the flow velocity is small in the beginning. However, because of the root stones movement at $\mathrm{t}=250 \mathrm{~s}$, the water flow is squeezed between the down cross corner and the root stones, so the flow velocity increases. Monitoring point 5 and monitoring point 6 are located in the connecting dam section. The whirlpool flow causes the water flow velocity to increase in both places. From the velocity variation of monitoring points, the flow velocity at monitoring point 5 is larger from $t=120 \mathrm{~s}$ to $\mathrm{t}=160 \mathrm{~s}$. And the flow velocity at monitoring point 6 is small at the early time, increases gradually at $\mathrm{t}=120 \mathrm{~s}$, and remains stable. According to Figure 17, the flow velocity changes smoothly in the upstream face and the upper cross corner. But due to the root stones movement, the flow rate changes greatly in the 


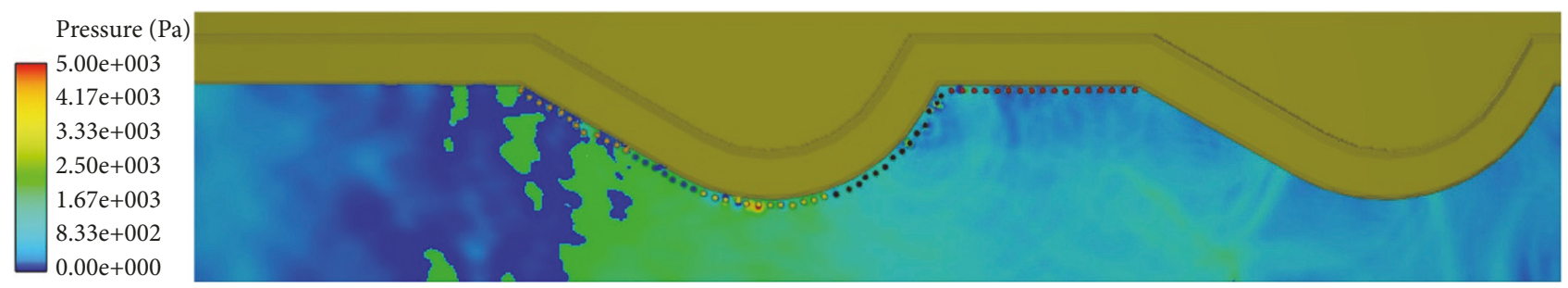

(a)

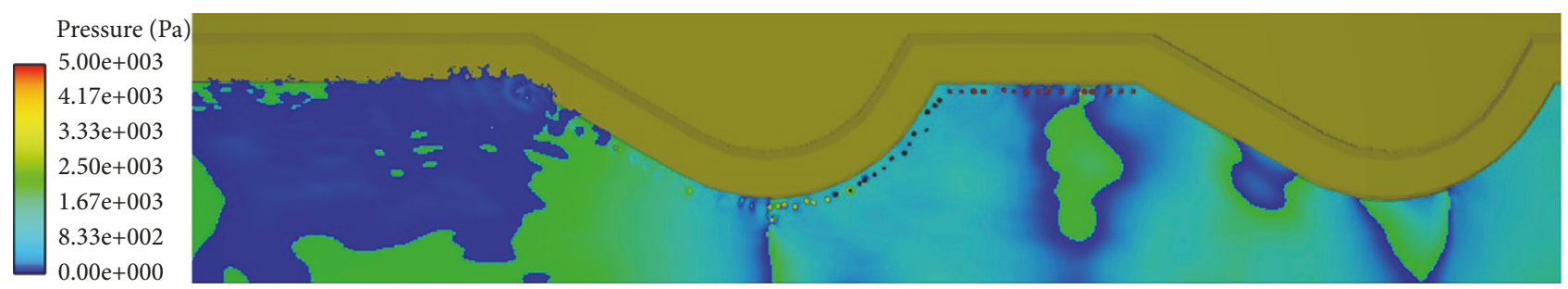

(b)

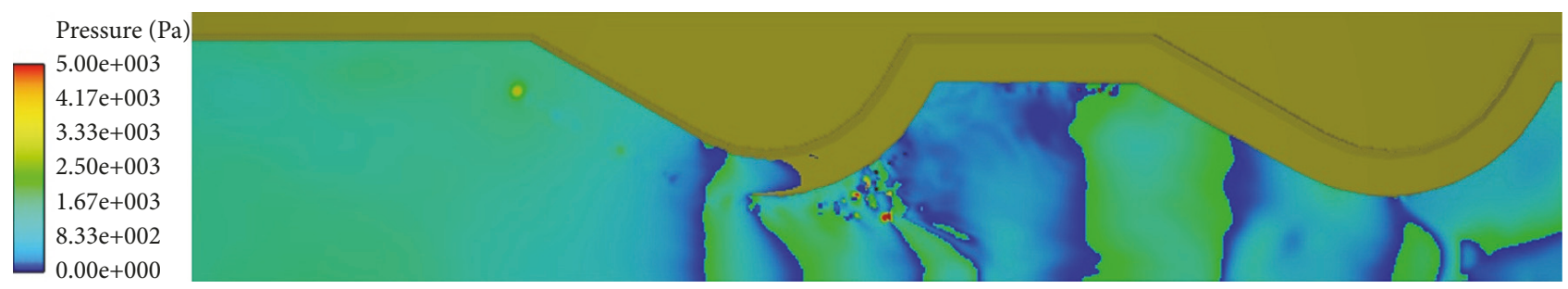

(c)

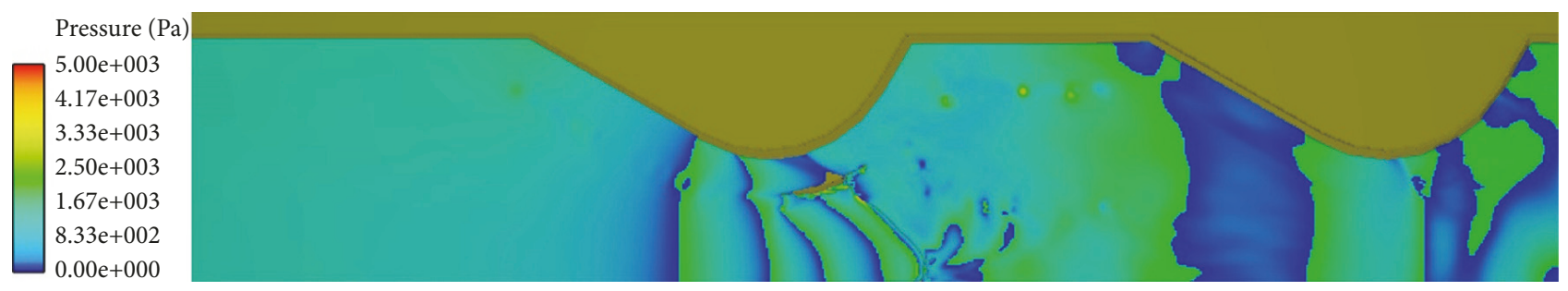

(d)

Figure 15: Pressure at different time points. (a) $\mathrm{T}=50 \mathrm{~s}$. (b) $\mathrm{T}=150 \mathrm{~s}$. (c) $\mathrm{T}=250 \mathrm{~s}$. (d) $\mathrm{T}=350 \mathrm{~s}$.

other areas. During the whole process, the flow velocity in the dam head is the largest, followed by the flow velocity in the upper cross corner, and the velocity in the upstream face and the down cross corner is smaller.

3.9. Analysis of Turbulent Energy. Figure 18 shows the water turbulent flow at different time points. At $\mathrm{t}=50 \mathrm{~s}$, there is no obvious generation of turbulent energy in the whole computational area. At $\mathrm{t}=150 \mathrm{~s}$, there is a slight water flow turbulent kinetic energy in the dam head. After passing through the dam head, the water flow is divided into two parts, and the water vortex generated in the dam crotch causes the water flow to have the turbulent energy. At $t=250 \mathrm{~s}$, the turbulent area continues to expand in the dam crotch. When the water flow is spreading among the root stones in the dam head and the down cross corner, the water flow generates turbulent kinetic energy. At $t=350 \mathrm{~s}$, the water flow generates large turbulent energy in the dam crotch. The water flow has obvious turbulent energy in the down cross corner, and the turbulent areas are the dam crotch and the connecting dam section. During the whole process, there is no obvious turbulence energy in the upstream face. The turbulent energy is obviously generated with the water flow spreading in the dam head and the down cross corner. Because of the current whirlpool, the water flow has larger turbulent energy in the dam crotch.

3.10. Analysis of Root Stones Loss. Figure 19 shows the root stones loss at different times. At $\mathrm{t}=50 \mathrm{~s}$, part of root stones in the upstream face move and the root stones in the dam head move slightly. After the water flows from the entrance boundary into the river, the water flows directly to the upstream face and collides with the bank slope. The collision water flow causes root stones to move slightly in this area, and the root stones have no obvious movement in the other areas. At $\mathrm{t}=150 \mathrm{~s}$, it is obvious to see that the root stones in the upper cross corner and dam head are away from the dam foundation. Combined with Figure 14(b), 


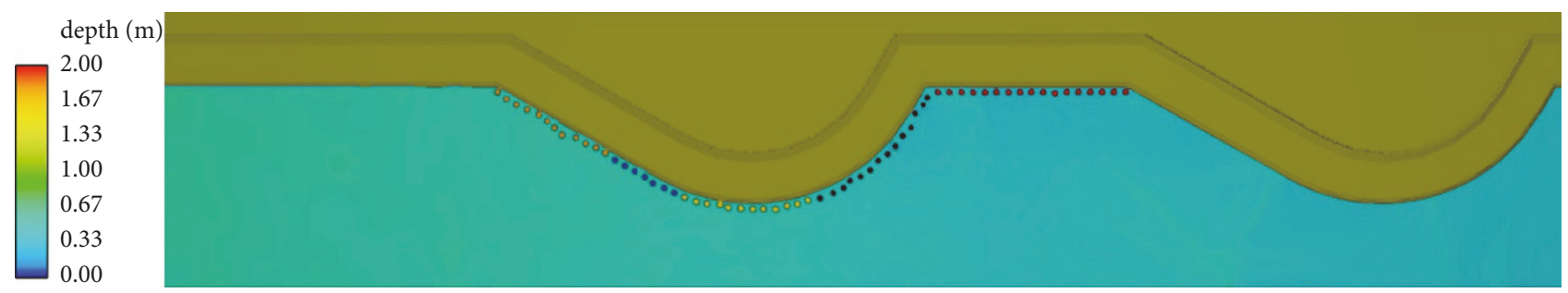

(a)

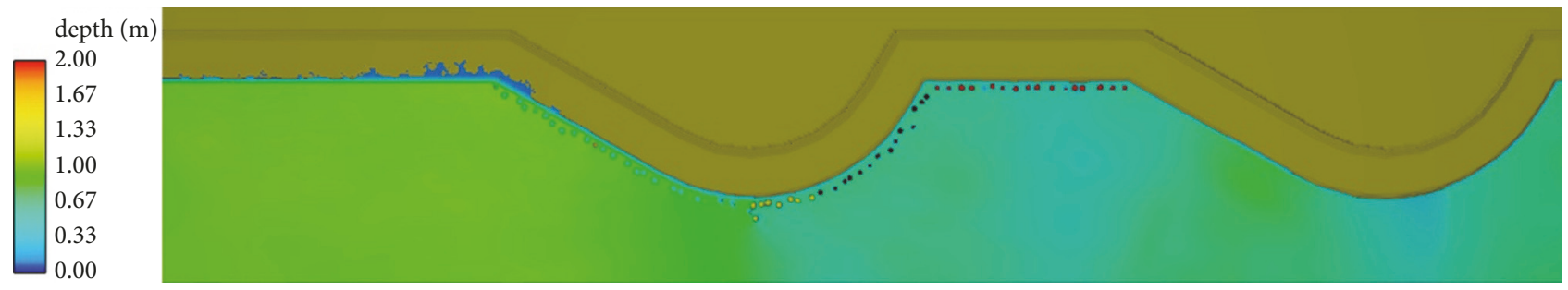

(b)

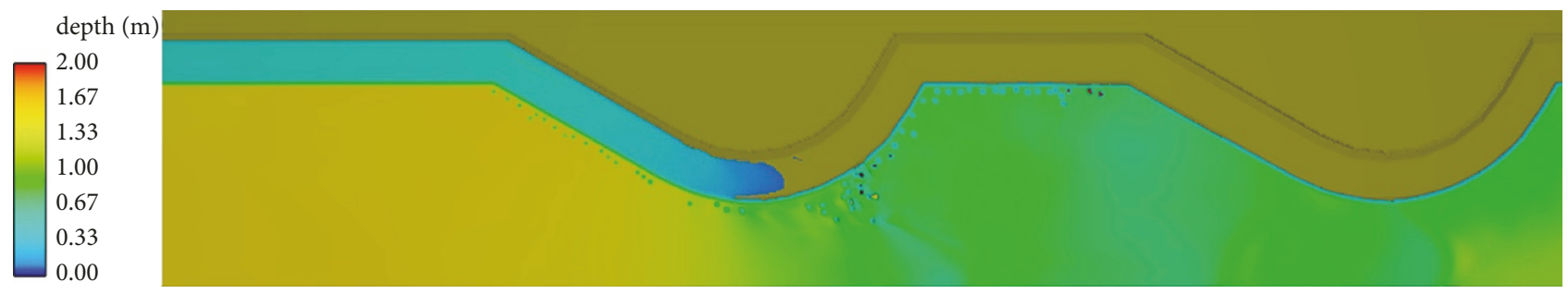

(c)

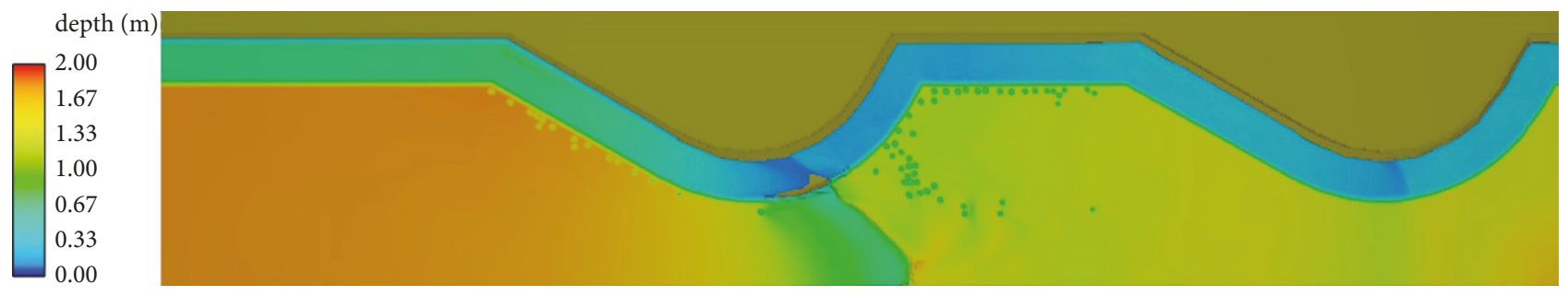

(d)

Figure 16: Flow depth at different time points. (a) $\mathrm{T}=50 \mathrm{~s}$. (b) $\mathrm{T}=150 \mathrm{~s}$. (c) $\mathrm{T}=250 \mathrm{~s}$. (d) $\mathrm{T}=350 \mathrm{~s}$.

when the water flow velocity is around $2 \mathrm{~m} / \mathrm{s}$, the root stones start to move, and then the root stones move downstream. Some root stones move slightly because of the action of water vortex in the down cross corner. At $\mathrm{t}=250 \mathrm{~s}$, most root stones in the dam head have been away from the original position. Combined with Figure 14(c), the maximum water flow velocity in dam head is around $2.5 \mathrm{~m} / \mathrm{s}$. And there is a whirlpool near the upstream face of the second dam buttress, and the root stones in the connecting dam section move upwards under the action of the vortex flow. At $t=350 \mathrm{~s}$, the root stones have an obvious movement in the upper cross corner and the dam head, and the water flow velocity is 3.5 $\mathrm{m} / \mathrm{s}$ in the dam head. Because the root stones in the dam head are away from the original position, after the water flow passes through the dam head, part of the water flows around the head of dam and causes the root stones to move in the down cross corner, and the root stones in the down cross corner are away from the dam foundation. But the distance of root stones loss in the down cross corner is much smaller than the distance of root stones loss in the upper cross corner and the dam head. During the whole simulation process, the root stones loss is the most serious in the dam head, followed by the root stones loss in the upper cross corner. The root stones are away from the original position in the down cross corner; there is basically no root stones loss in the upstream face. And most of the lost root stones stay around the down cross corner. Because of the action of the water vortex, the root stones in the connecting dam section and the dam crotch move upstream.

\section{Conclusions}

We established a mathematical model to study the root stones loss characteristics, analyzed the actual dam buttress project based on the FLOW-3D software, and drew the following conclusions: 


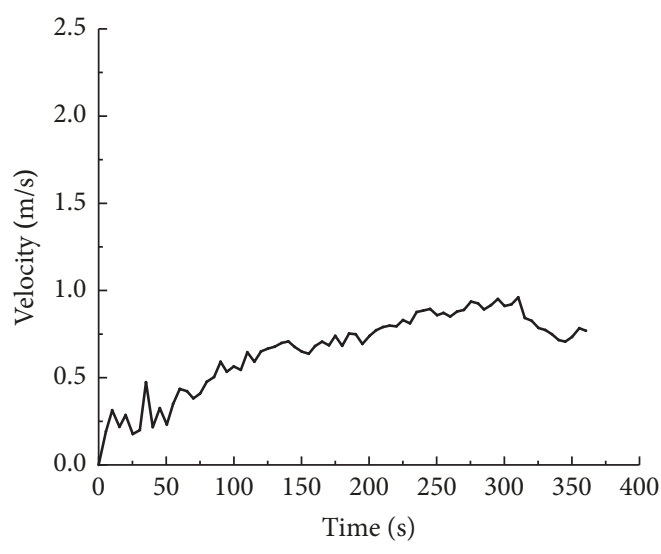

(a)

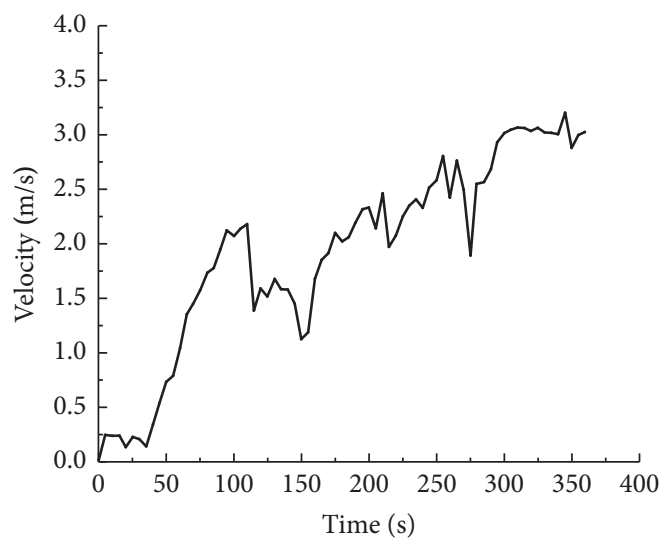

—_ Monitoring point 3

(c)

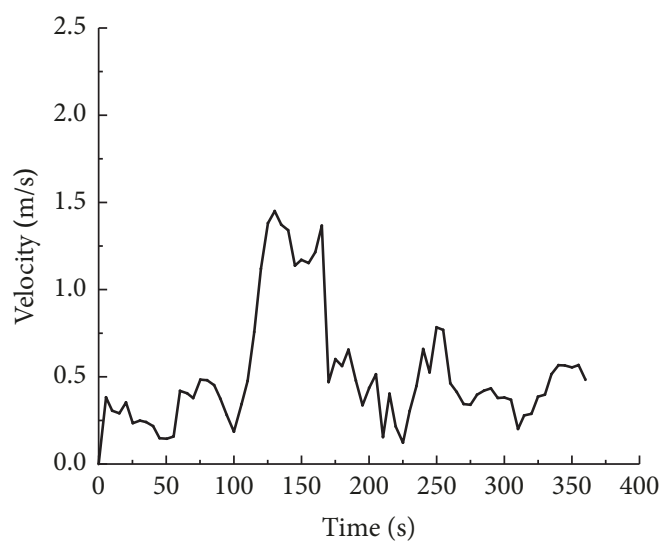

Monitoring point 5

(e)

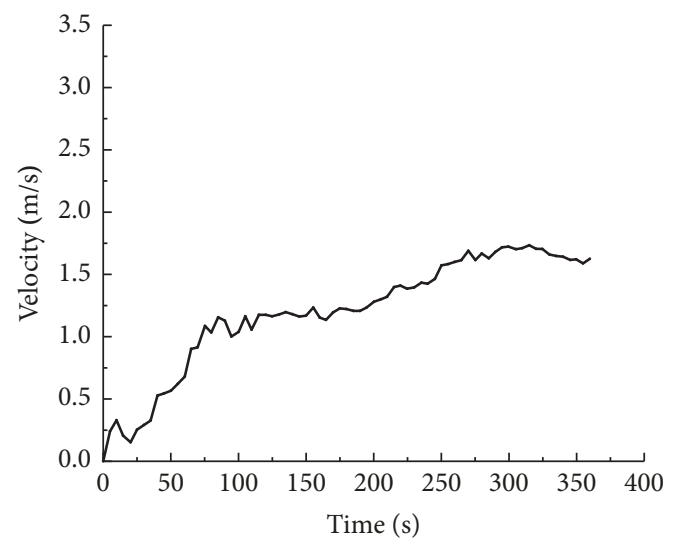

Monitoring point 2

(b)

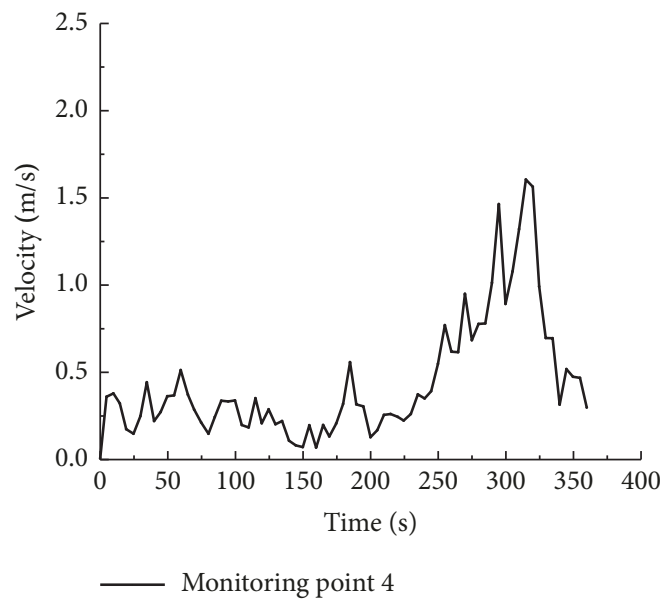

(d)

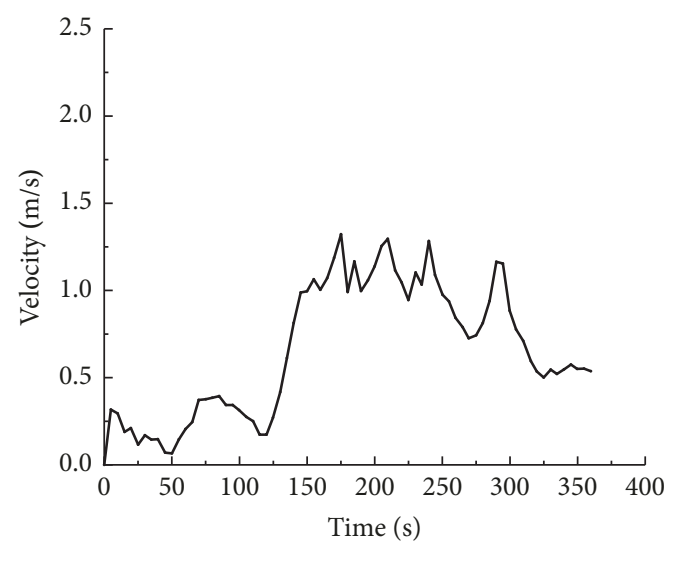

Monitoring point 6

(f)

FIGURE 17: Velocity of monitoring points. (a) Monitoring point 1. (b) Monitoring point 2. (c) Monitoring point 3. (d) Monitoring point 4. (e) Monitoring point 5. (f) Monitoring point 6.

(1) The flow velocity in the dam head is the highest in the whole calculation process. The root stones starting velocity in the dam head is around $2.0 \mathrm{~m} / \mathrm{s}$, and the maximum velocity can reach up to $3.6 \mathrm{~m} / \mathrm{s}$ when the flood happens. The velocity is smaller in the upstream face and the down cross corner, so the water flow has a smaller influence on the root stones.

(2) The numerical simulation results show that the root stones loss is serious in the upper cross corner and the dam 


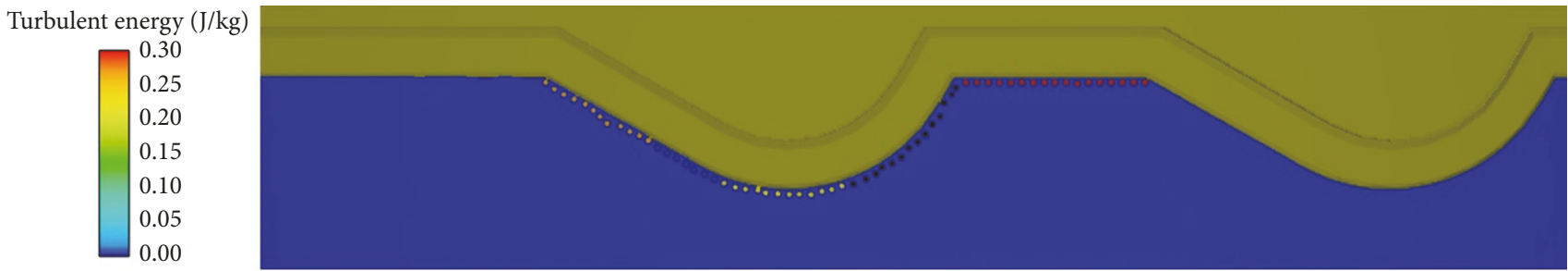

(a)

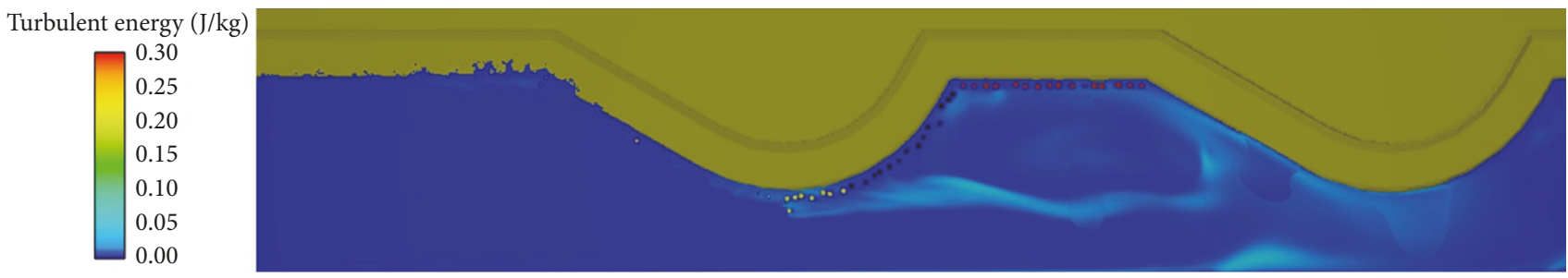

(b)

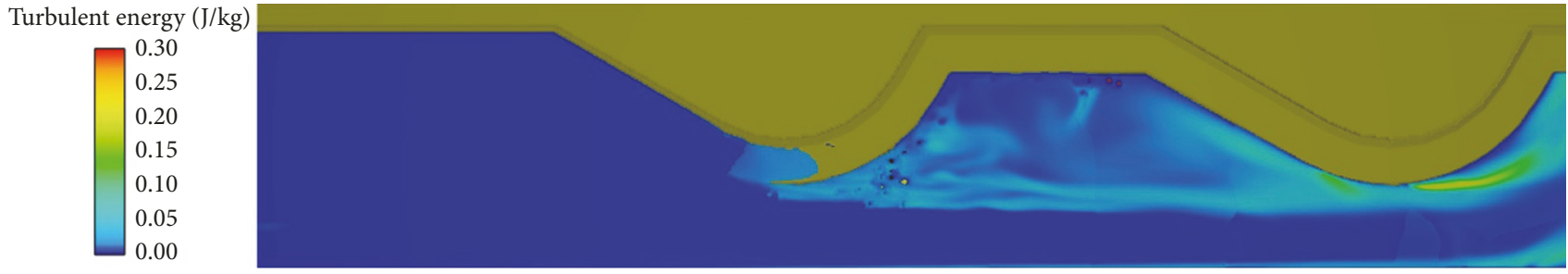

(c)

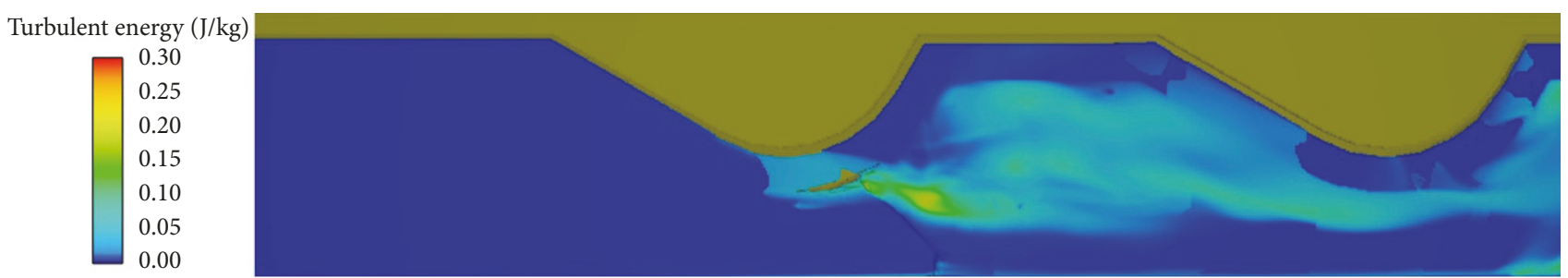

(d)

Figure 18: Turbulent energy. (a) $\mathrm{T}=50 \mathrm{~s}$. (b) $\mathrm{T}=150 \mathrm{~s}$. (c) $\mathrm{T}=250 \mathrm{~s}$. (d) $\mathrm{T}=350 \mathrm{~s}$.

head. A few of root stones are away from the original position, and most of lost root stones are gathered in the dam crotch.

(3) In the upper cross corner and the dam head, the root stones are mainly affected by the drag force and the lifting force of the water flow. And the root stones have an obvious loss in those two places. In the down cross corner and the connecting dam section, the root stones are mainly affected by the flow vortex force.

\section{Notations}

$A_{x}, A_{y}, A_{z}:$ Fractional area open to flow in $x, y, z$ direction, respectively

$C_{D}: \quad$ Drag force coefficient

$C_{\mu}: \quad 0.085$

$C_{1 \varepsilon}: \quad 1.42$

$C_{2 \varepsilon}: \quad 1.68$

$d: \quad$ The equivalent particle size

F: $\quad$ Grid ratio function
$F_{D}: \quad$ Drag force

$f_{x}, f_{y}, f_{z}$ : Viscous acceleration in $x, y, z$ direction, respectively

$G_{k}$ : The generation of turbulent energy $k$

$G_{x}, G_{y}, G_{z}$ : Body acceleration in $x, y, z$ direction, respectively

$k: \quad$ Turbulent energy

$P: \quad$ Pressure field

Re: $\quad$ Reynolds number

$U$ : The velocity of water flow

$u, v, w: \quad$ Current velocity component in $x, y, z$ direction, respectively

$V_{F}$ : $\quad$ Fractional volume open to flow

$x, y, z: \quad$ Direction in $N-S$ equation, respectively

$\rho: \quad$ Density of the fluid

$\varepsilon$ : $\quad$ Turbulent energy dissipation rate

$\mu_{i}$ : Turbulent kinematic viscous coefficient

$\begin{array}{ll}\sigma_{k}: & 0.7179\end{array}$

$\sigma_{\varepsilon}: \quad 0.7179$ 


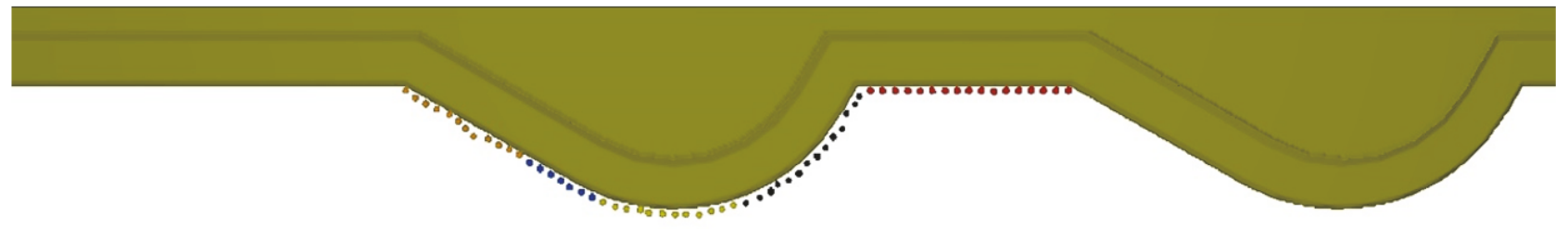

(a)

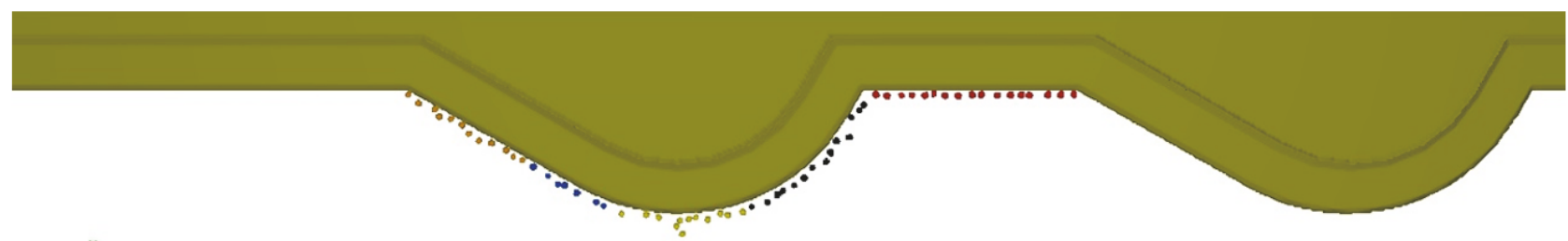

(b)
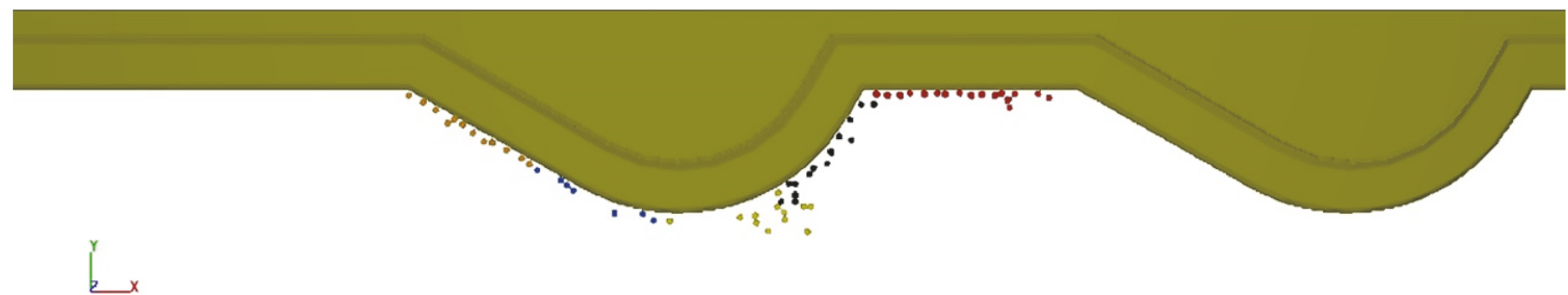

(c)

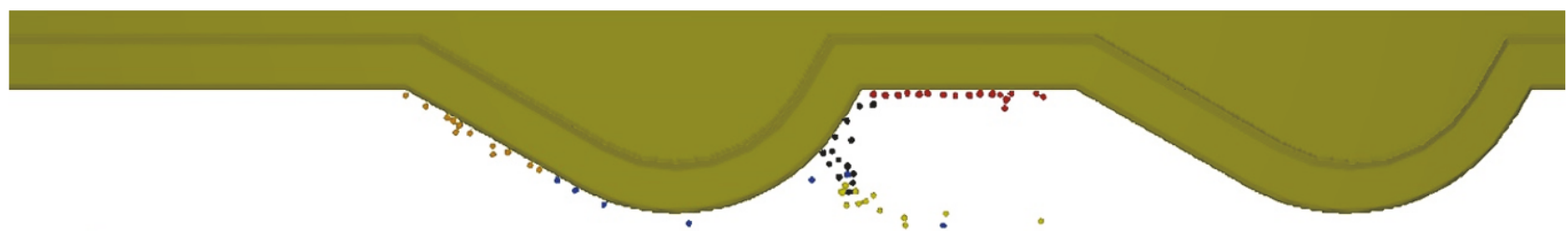

(d)

FIgURE 19: Root stones loss at different time points. (a) $\mathrm{T}=50 \mathrm{~s}$. (b) $\mathrm{T}=150 \mathrm{~s}$. (c) $\mathrm{T}=250 \mathrm{~s}$. (d) $\mathrm{T}=350 \mathrm{~s}$.

$\eta_{0}: 4.377$

$\beta: 0.012$.

\section{Data Availability}

The data used to support the findings of this study are included within the article.

\section{Conflicts of Interest}

The authors declare that there are no conflicts of interest regarding the publication of this paper.

\section{Acknowledgments}

This work was supported by National Natural Science Foundation of China (CN) [grant number 51509104], and National key R\&D program on monitoring, early warming and prevention of major natural disasters [grant number 2017YFC1501202]

\section{References}

[1] H. W. Zhang, J. Y. Wang, X. M. Ding, and B. H. Zhao, "Experimental study on the way to protect the root stones in the Yellow River dangerous works," in Governance the Yellow 
River science and technology information, vol. 4, pp. 60-65, 1989, http://www.cqvip.com/read/read.aspx ?id=11756158.

[2] Z. J. Zhang, The Study on the Experiment of the Scoured Pits of the Dam Buttress and the Runoff of Root Rocks of the Ningxia River Section of the Yellow River, vol. 3, Xi'an University of Technology, 2003.

[3] Y. Y. Gou, "Mechanics Analysis and Study of Root Rock Loss in River Channel Harness Projects," Yellow River, vol. 22, no. 4, pp. 4-5, 2000.

[4] J. J. Zhang, Y. X. Cui, and Z. J. Lian, "Reasons and protective measures of root stones loss in the Yellow River dam bank," Shandong Water Resources, vol. no. 6, p. 14, 2000.

[5] F. S. Zheng, T. P. Chen, and W. Guo, "Reasons and reinforcement measures of root stones loss in the river dam bank," Journal of Yellow River Conservancy Technical Institute, vol. 14, no. 1, pp. 14-15, 2002.

[6] J. Q. Bao, Q. Dong, and H. Wang, "Analysis on Causes of Foundation Rock Loss of River Training Works of the Yellow River and Measures for Prevention," Yellow River, vol. 25, no. 11, pp. 17-18, 2003.

[7] C. Y. Miao, X. F. Guo, and H. H. Qi, "Study on Root Rock Loss and Reinforcement of River Training Works of the Yellow River," Yellow River, vol. 26, no. 2, pp. 25-26, 2004.

[8] S. E. Coleman, B. W. Melville, and L. Gore, "Fluvial entrainment of protruding fractured rock," Journal of Hydraulic Engineering, vol. 129, no. 11, pp. 872-884, 2003.

[9] A. Bellini and V. Fiorotto, "Direct dynamic force measurement on slabs in spillway stilling basins," Journal of Hydraulic Engineering, vol. 121, no. 10, pp. 686-693, 1995.

[10] S. Malavasi and A. Guadagnini, "Hydrodynamic loading on river bridges," Journal of Hydraulic Engineering, vol. 129, no. 11, pp. 854-861, 2003.

[11] E. Naudascher and H.-J. Medlarz, "Hydrodynamic loading and backwater effect of partially submerged bridges," Journal of Hydraulic Research, vol. 21, no. 3, pp. 213-232, 1983.

[12] L. J. Zhu, J. Z. Wang, N. S. Cheng, Q. Ying, and D. F. Zhang, "Settling distance and incipient motion of sandbags in open channel flows," Journal of Waterway Port Coastal Ocean Engineering, vol. 130, no. 2, pp. 98-103, 2004.

[13] G. Alfonsi, A. Lauria, and L. Primavera, "Recent Results from Analysis of Flow Structures and Energy Modes Induced by Viscous Wave around a Surface-Piercing Cylinder," Mathematical Problems in Engineering, vol. 2017, Article ID 5875948, 10 pages, 2017.

[14] A. Iranmanesh and M. Passandideh-Fard, "A three-dimensional numerical approach on water entry of a horizontal circular cylinder using the volume of fluid technique," Ocean Engineering, vol. 130, pp. 557-566, 2017.

[15] A. C. Ekeleme and J. C. Agunwamba, "Experimental Determination of Dispersion Coefficient in Soil," Emerging Science Journal, vol. 2, no. 4, 2018.

[16] Md. Shahjahan Ali, Md. Milon Hasan, and Masuma Haque, "Two-Dimensional Simulation of Flows in an Open Channel with Groin-Like Structures by iRIC Nays2DH," Mathematical Problems in Engineering, vol. 2017, Article ID 1275498, 10 pages, 2017.

[17] Y.-Y. Gao, C.-S. Yin, H.-Q. Zhang, K. Yang, X.-Z. Zhao, and Z. Sun, "Numerical Study on Flow around Four Square-Arranged Cylinders at Low Reynolds Numbers," Mathematical Problems in Engineering, vol. 2017, Article ID 6381256, 18 pages, 2017.
[18] A. Movahedi, M. R. Kavianpour, and O. A. Yamini, "Evaluation and modeling scouring and sedimentation around downstream of large dams," Environmental Earth Sciences, vol. 77, no. 8, 2018.

[19] A. Sarhadi and E. Jabbari, "Investigating Effect of Different Parameters of the Submerged Vanes on the Lateral Intake Discharge Located in the 180 Degree Bend Using the Numerical Model," Civil Engineering Journal, vol. 3, no. 11, p. 1176, 2017.

[20] A. Movahedi, M. Kavianpour, and O. Aminoroayaie Yamini, "Experimental and numerical analysis of the scour profile downstream of flip bucket with change in bed material size," ISH Journal of Hydraulic Engineering, pp. 1-15, 2017.

[21] T. Sayeed, B. Colbourne, D. Molyneux, A. Akinturk, and H. Zaman, "Experimental and numerical investigation of wave induced motions of partially submerged bodies approaching a fixed structure," Ocean Engineering, vol. 155, pp. 115-130, 2018.

[22] A. R. Razavi and H. Ahmadi, "Numerical Modelling of Flow in Morning Glory Spillways Using FLOW-3D," Civil Engineering Journal, vol. 3, no. 10, p. 956, 2017.

[23] D. C. Lo, K. Murugesan, and D. L. Young, "Numerical solution of three-dimensional velocity-vorticity Navier-Stokes equations by finite difference method," International Journal for Numerical Methods in Fluids, vol. 47, no. 12, pp. 1469-1487, 2005.

[24] X. H. Lu, F. L. Yang, B. J. Dong, and B. Mao, "Investigation of turbulent channel flow and sediment transport using large-eddy simulation method," Engineering Journal of Wuhan University, vol. 49, no. 3, pp. 352-357, 2016.

[25] S. Razavi Alavi, E. Nemati Lay, and Z. Alizadeh Makhmali, "A CFD Study of Industrial Double-Cyclone in HDPE Drying Process," Emerging Science Journal, vol. 2, no. 1, 2018.

[26] V. Yakhot and S. A. Orszag, "Renormalization-group analysis of turbulence," Physical Review Letters, vol. 57, no. 14, pp. 17221724, 1986.

[27] E. Fadaei-Kermani, G. A. Barani, and M. Ghaeini-Hessaroeyeh, "Numerical Detection of Cavitation Damage on Dam Spillway," Civil Engineering Journal, vol. 2, no. 9, pp. 484-490, 2016, Http://civilejournal.org/index.php/cej/article/view/161.

[28] A. R. Razavi and H. Ahmadi, "Three-Dimensional Simulation of Flow Field in Morning Glory Spillway to Determine Flow Regimes (Case Study: Haraz Dam)," Civil Engineering Journal, vol. 3, no. 11, pp. 1133-1145, 2017.

[29] C. W. Hirt and B. D. Nichols, "Volume of fluid (VOF) method for the dynamics of free boundaries," Journal of Computational Physics, vol. 39, no. 1, pp. 201-225, 1981.

[30] C. W. Hirt and J. M. Sicilian, "A porosity technique for the definition of obstacles in rectangular cell meshes," in Proceedings of the Fourth International Conf Ship Hydro, National Academic of Science, Washington, Wash, USA, 1985.

[31] Y. Sadeghi Googheri, M. Saneie, and S. Ershadi, "ThreeDimension Numerical Simulation of Scour Temporal Changes due to Flow in the Downstream of Combined Weirs and Gate Model," Civil Engineering Journal, vol. 3, no. 11, p. 1111, 2017.

[32] J. B. Evett and C. Liu, Fundamentals of Fluid Mechanics, New York, MeGraw-Hill, 1987.

[33] Q. X. Pang, J. H. Xu, and H. X. Xin, "Effect of square-section cylinder shape on the drag force," Journal of Waterway and Harbor, vol. 27, no. 1, p. 22, 2006.

[34] X. K. Shen, "CJJ 56-2012 Code for geotechnical investigation of municipal engineering projects," China Architecture Building Press, 2012. 


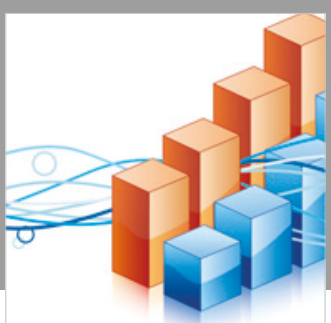

Advances in

Operations Research

\section{-n-m}
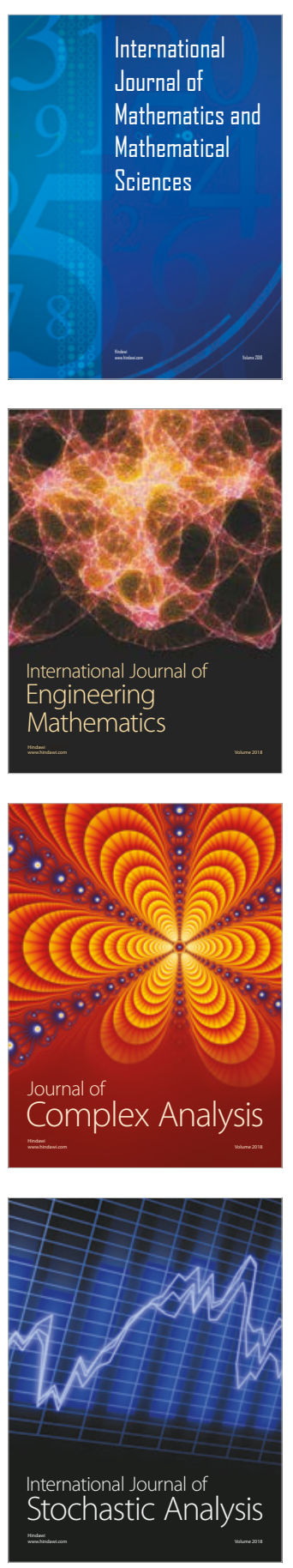
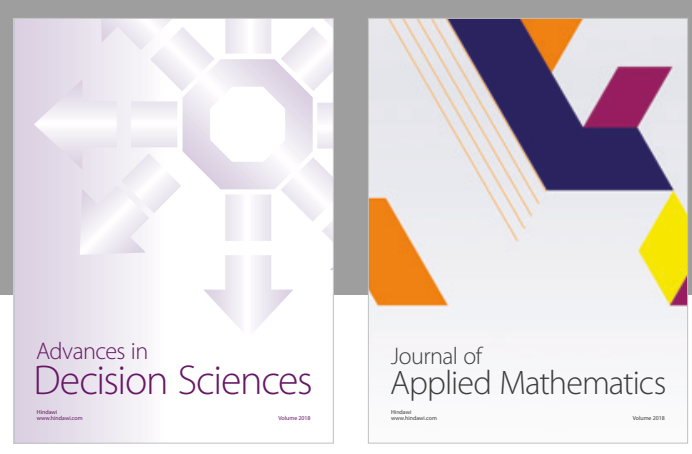

Journal of

Applied Mathematics
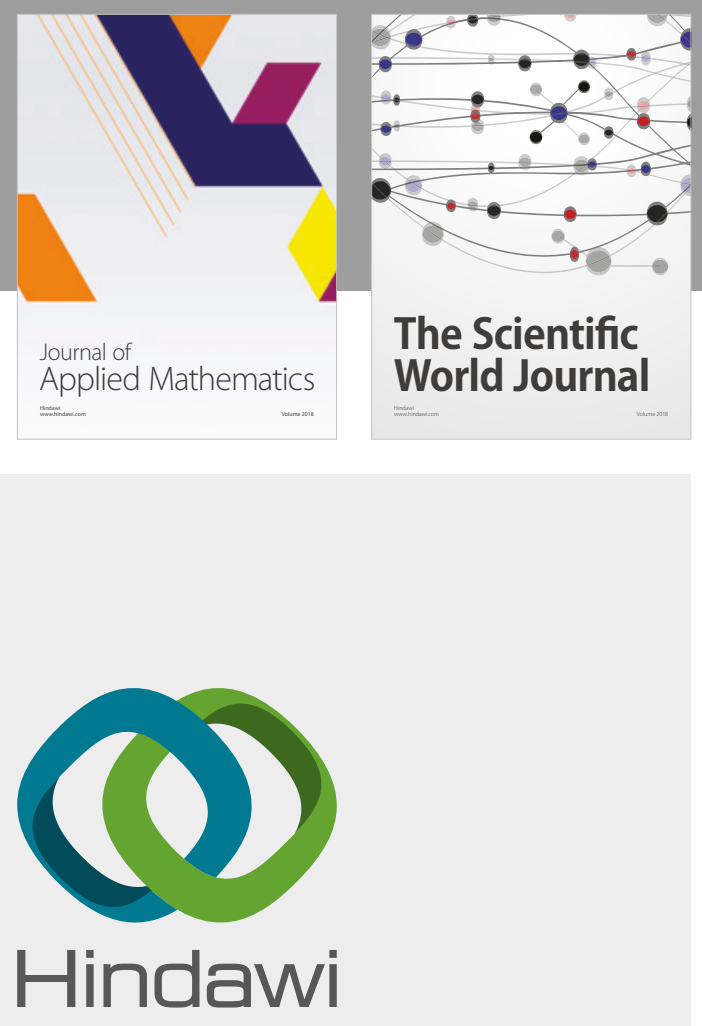

Submit your manuscripts at

www.hindawi.com

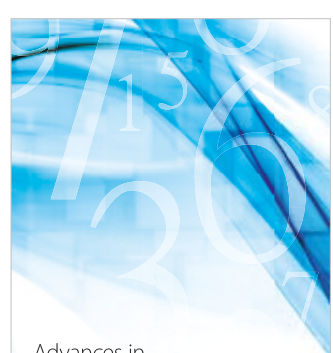

Advances in
Numerical Analysis
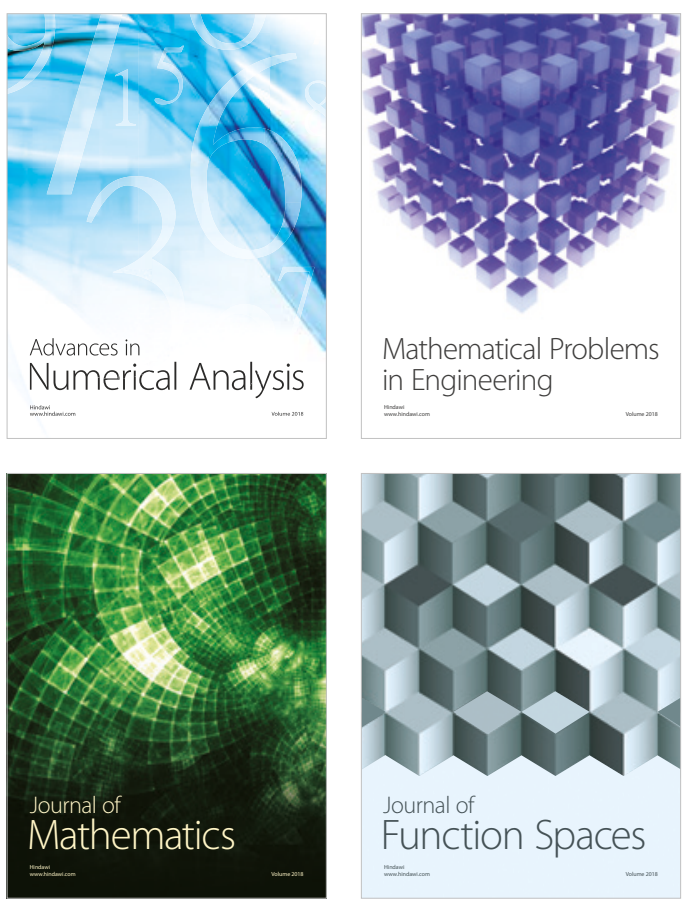

Mathematical Problems in Engineering

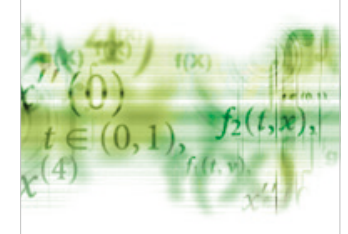

International Journal of

Differential Equations

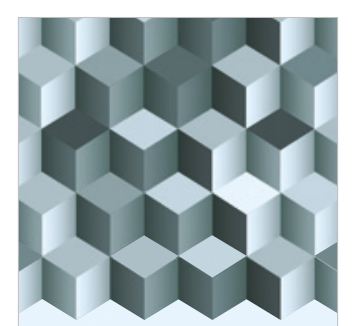

Journal of

Function Spaces

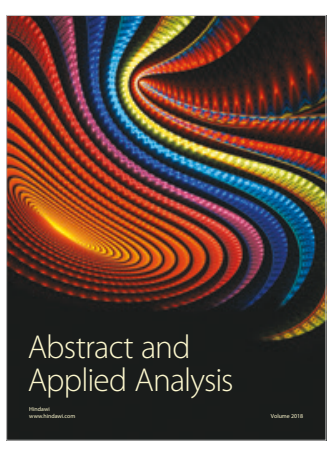

The Scientific

World Journal

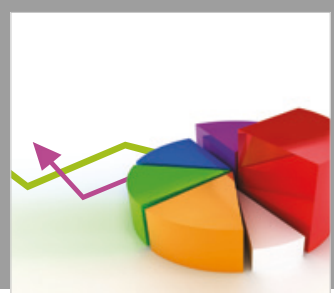

Journal of

Probability and Statistics
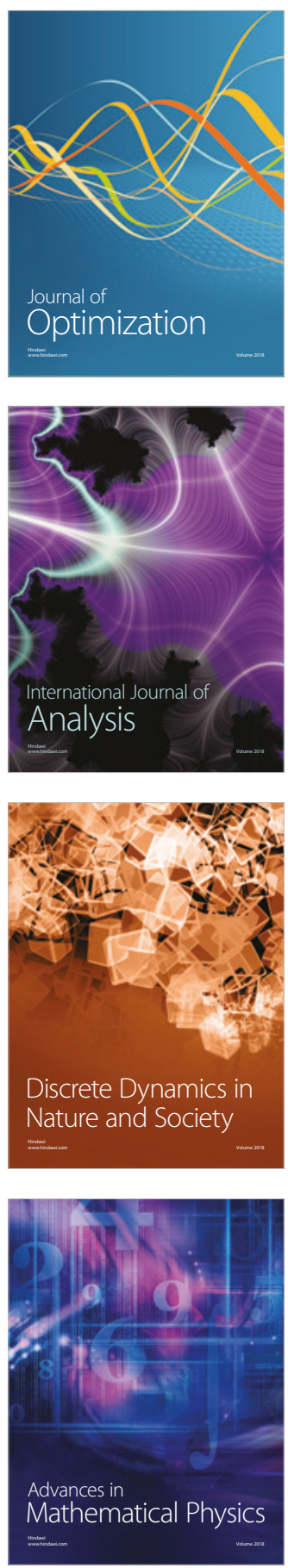